\title{
Hydrogen spillover and its relation to catalysis: observations on structurally defined single-atom sites
}

\section{Max Hülsey}

National University of Singapore https://orcid.org/0000-0002-9894-0492

\section{Victor Fung}

Oak Ridge National Laboratory

Ning Yan ( $\nabla$ ning.yan@nus.edu.sg )

National University of Singapore https://orcid.org/0000-0002-1877-9206

\section{Article}

Keywords: hydrogen spillover, catalytic hydrogenation, heterogeneous catalysis

Posted Date: June 8th, 2021

DOI: https://doi.org/10.21203/rs.3.rs-574294/v1

License: (1) (i) This work is licensed under a Creative Commons Attribution 4.0 International License.

Read Full License 


\title{
Hydrogen spillover and its relation to catalysis: observations on structurally defined single-atom sites
}

\author{
Max J. Hülsey, ${ }^{1,3}$ Victor Fung, ${ }^{2,3}$ Ning Yan ${ }^{1, *}$ \\ ${ }^{1}$ Department of Chemical and Biomolecular Engineering, National University of Singapore, 117585 \\ Singapore. \\ ${ }^{2}$ Center for Nanophase Materials Sciences, Oak Ridge National Laboratory, Oak Ridge, Tennessee \\ 37831, United States of America. \\ ${ }^{3}$ These authors contributed equally: Max J. Hülsey, Victor Fung. \\ * Corresponding author. Email: ning.yan@nus.edu.sg
}

\begin{abstract}
Hydrogen spillover, involving the transfer of $\mathrm{H}$ atoms from metal sites onto the catalyst support, is ubiquitous in chemical processes such as catalytic hydrogenation and hydrogen storage and is therefore of tremendous fundamental and technological interest. However, atomic level information concerning the kinetics of this process, the structural evolution of the catalysts during hydrogen spillover, as well as the nature of participation of the spilled over $\mathrm{H}$ in catalysis, remain vastly lacking. Here, we provide insights to those questions with the development of a solubilised polyoxometalate-supported singleatom catalyst which allows for the use of characterisation techniques generally inaccessible to study heterogeneous catalysis. Hydrogenation kinetics together with poisoning studies further reveal that hydrogen spillover can be either detrimental or beneficial for catalysis - the direction and magnitude of which depends predominantly on the nature of the reducible bond in the substrate. Similar trends were observed on one of the most prototypical hydrogen spillover catalysts, $\mathrm{Pt} / \mathrm{WO}_{3}$, supporting the generalisability of the observations.
\end{abstract}

\section{Introduction}

Previously studied catalysts exhibiting hydrogen spillover only offer limited insights due to their lack of well-defined structures, insufficient tools to precisely characterise spillover stoichiometries and kinetics, as well as the lack of information on the role of spilled over hydrogen during catalysis. ${ }^{1}$ For example, conventional nanoparticle catalysts on metal oxides such as the prototypical $\mathrm{Pt} / \mathrm{WO}_{3}$ comprise 
ill-defined metallic hydrogen splitting sites as well as complex metal support interfaces. Furthermore, ambiguities exist about whether spilled over $\mathrm{H}$ should be rather regarded as hydrogen atoms or protons. ${ }^{2}$ Although surface science studies offer deeper insights, correlating hydrogen spillover with catalytic activity remains difficult. ${ }^{3-5}$ In most cases, the support covered in spilled over hydrogen is viewed as a $\mathrm{H}$ reservoir with the metallic site as the main driver for catalysis, though in certain cases the direct participation of the H-covered support in hydrogenation reactions has been hypothesised. ${ }^{1,6}$ Besides constraints by the catalyst materials, techniques to study the hydrogen spillover phenomenon are additionally restricted to solid state $\mathrm{NMR},{ }^{7}$ temperature-programmed reactivity studies, ${ }^{8,9}$ neutron scattering, ${ }^{10}$ resonant photoemission ${ }^{11}$ and X-ray absorption spectroscopy ${ }^{12}$, among others, all with known limitations in the investigation of heterogeneous catalysts. DFT calculations can offer additional details but the relevance of those results is compromised by the lack of definedness of the spillover catalysts.

Due to these limitations, several major questions remain unanswered about hydrogen spillover: (i) the kinetics of the process, i.e. how the rate of $\mathrm{H}$ spillover is affected by an intermediate spillover state, (ii) the composition and properties of the catalyst after $\mathrm{H}$ spillover, and (iii) how the spilled over $\mathrm{H}$ contributes to heterogeneous hydrogenation catalysis. Herein, we provide insights to those questions by characterising the hydrogen spillover behaviour of several solubilised lacunary polyoxometalate (POM)-based single-atom catalysts (SACs). Previously, we reported similar catalysts to identify active sites during hydrogenation, as well as the $\mathrm{CO}$ and benzyl alcohol oxidation reactions. ${ }^{13-16}$ Herein, we find a unique interplay between positively charged Pd and a reducible Mo-based support for hydrogen spillover. Due to the solubility of the SAC in polar solvents, techniques like electrospray ionisation mass spectrometry (ESI-MS), liquid phase ${ }^{1} \mathrm{H}$ NMR and UV-Vis spectroscopy become viable tools for the characterisation of the process. Based on reaction kinetics, catalyst poisoning, and ESI-MS, we identified subtleties in the contribution of spilled over $\mathrm{H}$ to the hydrogenation of different substrates. These molecularly defined catalyst model structures with experimentally proven reaction intermediates provide an ideal system for DFT calculations to understand both thermodynamic and kinetic behaviour 
of hydrogen spillover. Combined with analogous experiments with $\mathrm{Pt} / \mathrm{WO}_{3}$ catalysts, it appears that our findings are not only true for SACs but may be generally applicable.

\section{Results and discussion}

\section{Hydrogen spillover on $\mathrm{PMo}_{11} \mathrm{O}_{39} \mathrm{Pd}_{1}$}

SACs based on lacunary POMs offer advantages such as easy synthesis, stable structures in 1:1 metal support ratios, as well as their high solubility in polar solvents. ${ }^{16} \mathrm{PMo}_{11} \mathrm{O}_{39}$ was synthesised by the lithium carbonate-mediated removal of one MoO subunit from phosphomolybdic acid (Supplementary Fig. 1) while $\mathrm{PW}_{11} \mathrm{O}_{39}$ was synthesised following the procedure described in our previous study. ${ }^{16}$ Mixing equimolar ratios of the lacunary POM and metal salts with weakly coordinating ligands yielded in situ the active site, $\mathrm{PMo}_{11} \mathrm{O}_{39} \mathrm{Pd}_{1}$, which can be easily and unambiguously characterised by electrospray ionisation mass spectrometry (ESI-MS) $\left(\left\{\left[\mathrm{PMo}_{11} \mathrm{O}_{39} \mathrm{Pd}_{1}\right]+2 \mathrm{H}^{+}\right\}^{3-}(\right.$ calc.: 606.55 , expt.: 606.57; the formula in the bracket indicates the composition of the catalytic sites whereas the two protons are captured from the solvent in the ionization chamber). When $\mathrm{PMo}_{11} \mathrm{O}_{39} \mathrm{Pd}_{1}$ was exposed to $\mathrm{H}_{2}$ at room temperature, a gradual colour change from yellow to blue was observed. ESI-MS of the solution after colour change suggested the formation of catalyst species containing spilled over hydrogen. The $\mathrm{m} / \mathrm{z}$ values of the catalyst after $\mathrm{H}_{2}$ exposure for $60 \mathrm{~min}$ were consistent with the formation of $\left\{\left[\mathrm{PMo}_{11} \mathrm{O}_{39} \mathrm{Pd}_{1}-\mathrm{H}_{16}\right]+3 \mathrm{H}^{+}\right\}^{2-}($ calc.: 917.89 , expt.: 917.86) with 16 spilled over $\mathrm{H}$ atoms on the $\mathrm{POM}$ (Fig. 1a, b and Supplementary Fig. 2). We did not observe any species with higher $\mathrm{H}$ coverage suggesting that this is the highest hydrogen spillover state of $\mathrm{PMo}_{11} \mathrm{O}_{39} \mathrm{Pd}_{1}$ under the reaction conditions. The lack of colour changes and unaltered ESI-MS spectra of $\mathrm{PMo}_{11} \mathrm{O}_{39}, \mathrm{PW}_{11} \mathrm{O}_{39} \mathrm{Pd}_{1}, \mathrm{PMo}_{11} \mathrm{O}_{39} \mathrm{Rh}_{1}$, and $\mathrm{PMo}_{11} \mathrm{O}_{39} \mathrm{Pt}_{1}$ after $\mathrm{H}_{2}$ exposure revealed that none of those exhibit a similar behaviour suggesting that the combination of Mo-based POMs and Pd has unique properties (Extended Data Fig. 1). UV-Vis spectroscopy of the Pd-Mo POM system showed the formation of two distinct states with absorption maxima at 700 and $316 \mathrm{~nm}$, respectively. This indicates significant changes in the electronic state of the POM-based SAC as should be expected from the oxidation state change of Mo. Reduction of $\operatorname{Mo}(\mathrm{VI})$ to $\mathrm{Mo}(\mathrm{V})$ often leads to absorption at $600-800 \mathrm{~nm}^{17,18}$ while more significant reduction of the POM changes the colour to a deep blue in this case with the absorption maximum in the UV region. The occurrence of two distinct maxima observed by UV-Vis spectroscopy implies the formation of two 
sets of species during hydrogen spillover (Fig. 1c). ESI-MS at different times of $\mathrm{H}_{2}$ exposure further supports the notion that distinct states of hydrogen spillover exist with a group of intermediate species (plausibly ranging from 8 to 12 or $14 \mathrm{H}$ atoms) with the ESI-MS peak centred at around $\left\{\left[\mathrm{PMo}_{11} \mathrm{O}_{39} \mathrm{Pd}_{1-}\right.\right.$ $\left.\left.\mathrm{H}_{12}\right]+3 \mathrm{H}^{+}\right\}^{2-}$ (calc.: 915.88, expt.: 915.84) (Fig. 1b and Supplementary Fig. 2), before reaching the saturated state of $\left[\mathrm{PMo}_{11} \mathrm{O}_{39} \mathrm{Pd}_{1}-\mathrm{H}_{16}\right] .{ }^{1} \mathrm{H}$ NMR of the catalyst before and after $24 \mathrm{~h} \mathrm{H}_{2}$ exposure in $\mathrm{d}^{6}-$ DMSO showed well-resolved and sharp resonances of spilled over $\mathrm{H}$. The strong downfield shift of the ${ }^{1} \mathrm{H}$ NMR signals highlight the electron-deficient nature of the spilled over $\mathrm{H}$ which thus should be viewed as protons on the reduced $\mathrm{PMo}_{11} \mathrm{O}_{39} \mathrm{Pd}_{1}$ (Fig. 1d and Supplementary Fig. 3). Integrated ratios between the ${ }^{1} \mathrm{H}$ resonances $(1: 1: 1: 1)$ corroborate the formation of $\left[\mathrm{PMo}_{11} \mathrm{O}_{39} \mathrm{Pd}_{1}-\mathrm{H}_{16}\right]$ as identified by ESI-MS. 

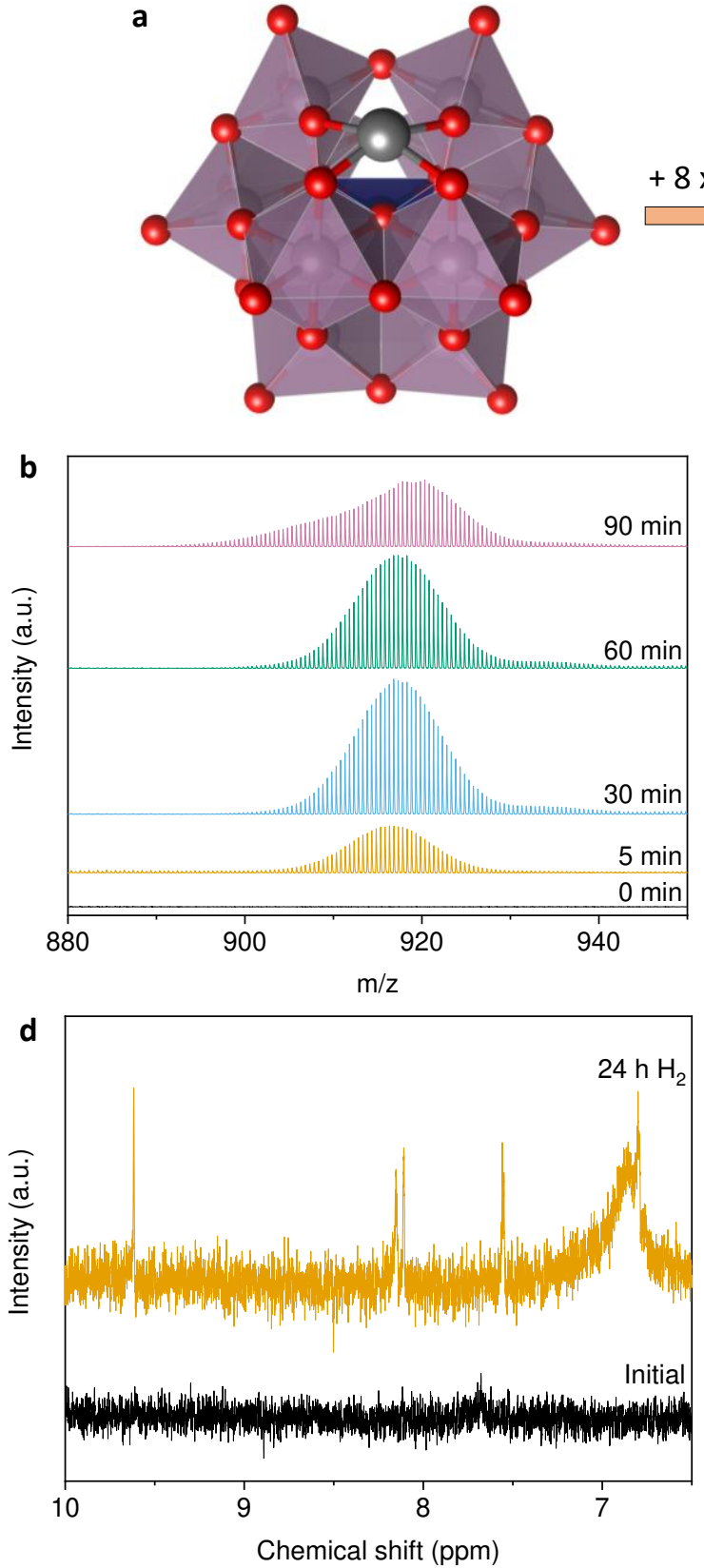
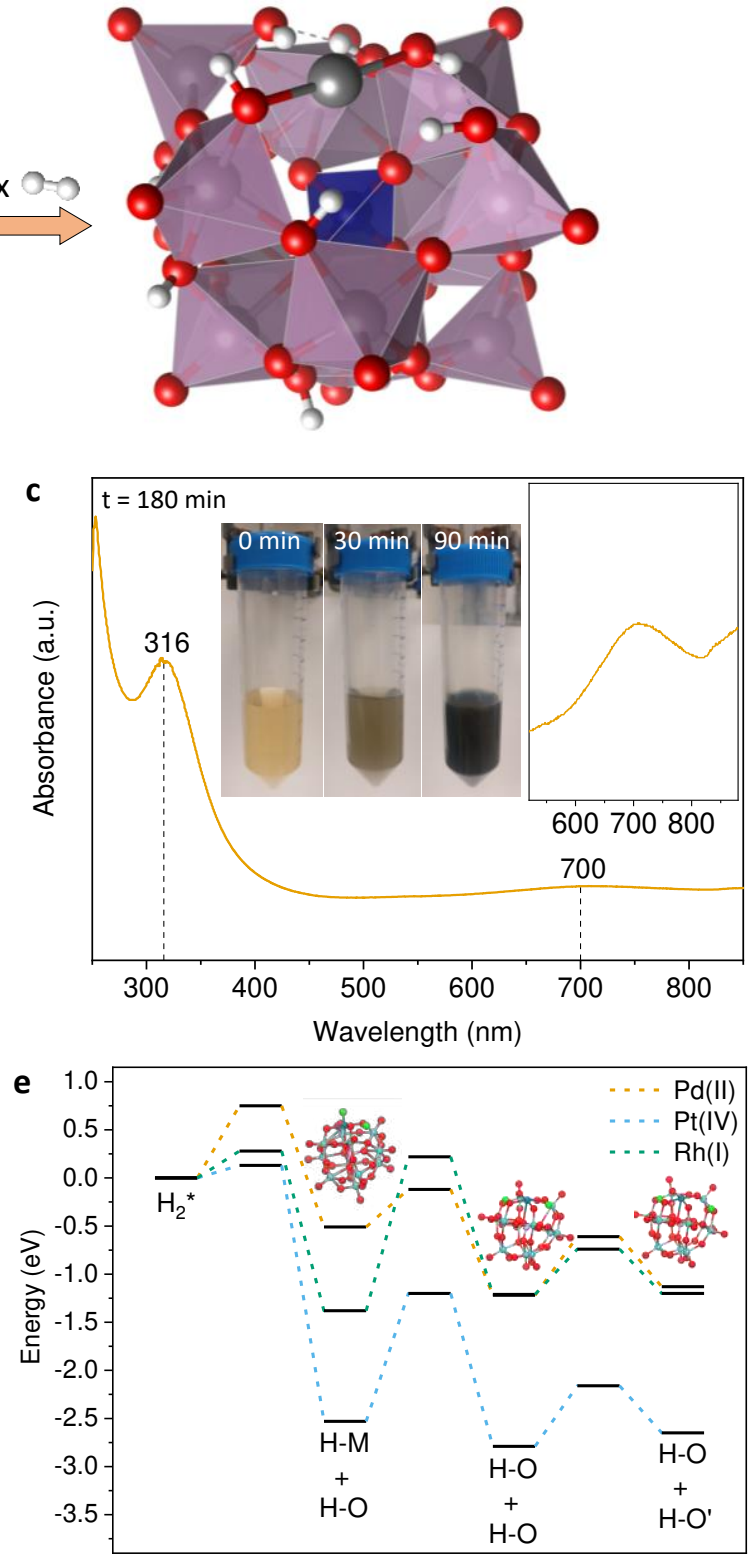

Reaction coordinate

Fig. 1 | Structure of $\mathrm{PMo}_{11} \mathrm{O}_{39} \mathbf{P d}_{1}$ after hydrogen spillover. a, Catalyst structure before and after full hydrogen spillover (16 H atoms) based on DFT calculations. Colour code - grey: Pd, pink: Mo, blue: $\mathrm{P}$, red: O, white: $\mathrm{H}$. b, ESI-MS of $\mathrm{PMo}_{11} \mathrm{O}_{39} \mathrm{Pd}_{1}$ during the hydrogen spillover for different durations. c, UV-Vis spectroscopy of $\mathrm{PMo}_{11} \mathrm{O}_{39} \mathrm{Pd}_{1}$ during the hydrogen spillover $(180 \mathrm{~min})$, photographs of the solution at different time points are shown in the inset. d, ${ }^{1} \mathrm{H}$ NMR of $\mathrm{PMo}_{11} \mathrm{O}_{39} \mathrm{Pd}_{1}$ before and after 24 h hydrogen spillover. e, DFT-calculated reaction energies of the $\mathrm{H}_{2}$ dissociation and spillover on different $\mathrm{PMo}_{11} \mathrm{O}_{39} \mathrm{M}_{1}$ catalysts. Colour code - grey: $\mathrm{Pd}$, light blue: Mo, pink: $\mathrm{P}$, red: $\mathrm{O}$, green: $\mathrm{H}$.

From these, we propose two subsequent steps to occur with $\mathrm{PMo}_{11} \mathrm{O}_{39} \mathrm{Pd}_{1}$ during $\mathrm{H}_{2}$ exposure:

$$
\begin{gathered}
\mathrm{PMo}_{11} \mathrm{O}_{39} \mathrm{Pd}_{1}+\mathrm{x} / 2 \mathrm{H}_{2} \rightarrow \mathrm{PMo}_{11} \mathrm{O}_{39} \mathrm{Pd}_{1}-\mathrm{H}_{\mathrm{x}}(8 \leq \mathrm{x} \leq 14, \text { intermediate state }) \\
\mathrm{PMo}_{11} \mathrm{O}_{39} \mathrm{Pd}_{1}-\mathrm{H}_{\mathrm{x}}+(16-\mathrm{x}) / 2 \mathrm{H}_{2} \rightarrow \mathrm{PMo}_{11} \mathrm{O}_{39} \mathrm{Pd}_{1}-\mathrm{H}_{16}(\mathrm{H} \text { fully covered state })
\end{gathered}
$$


From the ESI-MS analysis of the hydrogen spillover process after elongated times (90 min or longer), the formation of an oxygen vacancy from $\left\{\left[\mathrm{PMo}_{11} \mathrm{O}_{39} \mathrm{Pd}_{1}-\mathrm{H}_{16}\right]+3 \mathrm{H}^{+}\right\}^{2-}$ started to occur as evidenced by a mass loss of one oxygen. This is corroborated by the fragmentation of the $\left\{\left[\mathrm{PMo}_{11} \mathrm{O}_{39} \mathrm{Pd}_{1}-\mathrm{H}_{16}\right]+\right.$ $\left.3 \mathrm{H}^{+}\right\}^{2-}$ showing the formation of $\left\{\left[\mathrm{PMo}_{11} \mathrm{O}_{38} \mathrm{Pd}_{1}-\mathrm{H}_{14}\right]+3 \mathrm{H}^{+}\right\}^{2-}$ with the removal of one molecule of $\mathrm{H}_{2} \mathrm{O}$ (Supplementary Fig. 4).

$$
\mathrm{PMo}_{11} \mathrm{O}_{39} \mathrm{Pd}_{1}-\mathrm{H}_{16} \rightarrow \mathrm{PMo}_{11} \mathrm{O}_{38} \mathrm{Pd}_{1}-\mathrm{H}_{14}+\mathrm{H}_{2} \mathrm{O}
$$

Oxygen vacancy formation is often believed to be intimately related to hydrogenation/deoxygenation reactions (vide infra). ${ }^{19,20}\left\{\left[\mathrm{PMo}_{11} \mathrm{O}_{39} \mathrm{Pd}_{1}-\mathrm{H}_{16}\right]+3 \mathrm{H}^{+}\right\}^{2-}$ was completely EPR silent suggesting the absence of EPR-active Mo(V) species (Extended Data Fig. 2). Therefore, we conclude that the Mobased POM contains a mixture of Mo(IV) and Mo(VI) after hydrogen spillover. ${ }^{8}$ Of note, the hydrogen spillover was reversible within a few hours exposure to air at ambient conditions (Supplementary Fig. $5)$.

DFT calculations were employed to identify why the combination of $\mathrm{PMo}_{11} \mathrm{O}_{39}$ and $\mathrm{Pd}$ is special for hydrogen spillover. Complexes between the lacunary POM and $\mathrm{Pd}(\mathrm{II}), \mathrm{Pt}(\mathrm{IV})$, and $\mathrm{Rh}(\mathrm{I})$ were considered. For all catalysts, only the heterolytic splitting of $\mathrm{H}_{2}$ into metal-based $\mathrm{H}^{-}$and $\mathrm{POM}$-based $\mathrm{H}^{+}$ were feasible mechanisms. Interestingly, $\mathrm{Pd}(\mathrm{II})$ exhibited the highest $\mathrm{H}_{2}$ dissociation barriers, while $\mathrm{Pt}(\mathrm{IV})$ and $\mathrm{Rh}(\mathrm{I})$ split $\mathrm{H}_{2}$ almost without barriers. The subsequent step of $\mathrm{H}$ transfer from the metal to the support are essential for the hydrogen spillover process. For this step, $\mathrm{Pd}(\mathrm{II})$ demonstrated the lowest barriers, whereas activation energies were $>1.5 \mathrm{eV}$ for $\mathrm{Pt}(\mathrm{IV})$ and $\mathrm{Rh}(\mathrm{I})$, thus rendering $\mathrm{H}$ spillover virtually impossible at room temperature. Hydrogen diffusion barriers between $\mathrm{O}$ atoms on the support were low $(\sim 0.5 \mathrm{eV})$ and only marginally affected by the single metal cation (Fig. 1e). Next, the hydrogen spillover capacity of $\mathrm{PMo}_{11} \mathrm{O}_{39} \mathrm{Pd}_{1}$ was investigated by obtaining the average hydrogen adsorption energy relative to $\mathrm{H}_{2}$ gas as a function of $\mathrm{H}$ coverage (Supplementary Fig. 6). Consistent with experimental data, $16 \mathrm{H}$ atoms appear to be the approximate limit upon which further $\mathrm{H}$ spillover becomes endothermic, suggesting that the maximum $\mathrm{H}$ coverage is determined by thermodynamic rather than kinetic limitations. 
Those results support our observations that metal-POM combinations other than $\mathrm{PMo}_{11} \mathrm{O}_{39} \mathrm{Pd}_{1}$ do not show hydrogen spillover as well as the catalyst:H ratios after hydrogen spillover based on ESI-MS and ${ }^{1} \mathrm{H}$ NMR. DFT calculations further investigated the impact of POM composition on the $\mathrm{H}_{2}$ splitting behaviour (Supplementary Text, Supplementary Fig. 7, and Supplementary Table 1). Although hydrogen spillover from metallic Pt to various reducible supports has been proven, previous experiments also suggested that cationic Pt behaves very differently compared to its metallic counterpart. ${ }^{3,4,8}$

\section{Kinetics of the hydrogen spillover:}

The distinction of two related spillover species by UV-Vis provides us with a direct and non-destructive tool to follow hydrogen spillover kinetics. The formation of the first set of stable spillover intermediates with its UV-Vis absorbance at $700 \mathrm{~nm}$ has a positive order towards $\mathrm{H}_{2}$ concentration (1.52) confirming that $\mathrm{H}$ is involved in the rate-determining step and that the spillover entails multiple elementary steps (Fig. 2a). We further observed a negative order towards the concentration of $\mathrm{PMo}_{11} \mathrm{O}_{39} \mathrm{Pd}_{1}(-0.99)$ (Fig. $2 b)$. With this, the apparent activation enthalpy and entropy were determined to be $55.2( \pm 1.7) \mathrm{kJ} \mathrm{mol}^{-}$ ${ }^{1}$ and $-133.5( \pm 7.8) \mathrm{J} \mathrm{mol}^{-1} \mathrm{~K}^{-1}$, respectively (Fig. 2c). Hydrogen spillover overall is an entropically disfavoured process and thus it is reasonable to assume that the apparent activation entropy is also negative.

It is interesting to note that $\left\{\left[\mathrm{PMo}_{11} \mathrm{O}_{39} \mathrm{Pd}_{1}-\mathrm{H}_{12}\right]+3 \mathrm{H}^{+}\right\}^{2-}$ was the most abundant intermediate detected while no intermediates with low $\mathrm{H}$ coverage (i.e. below approximately $8 \mathrm{H}$ ) was observed. An analysis of the impact of $\mathrm{H}$ coverage on the $\mathrm{H}_{2}$ splitting barriers reveals a continuous decrease in $\mathrm{H}_{2}$ activation barrier on $\mathrm{PMo}_{11} \mathrm{O}_{39} \mathrm{Pd}_{1}$ as hydrogen spillover progresses (Extended Data Fig. 3). Noticeably, the hydrogen splitting mechanism also changes from a heterolytic to a homolytic with higher $\mathrm{H}$ coverage. At higher coverage, the activation barriers for $\mathrm{H}_{2}$ splitting become almost negligible and thus we can assume the transfer of $\mathrm{H}$ from the $\mathrm{Pd}$ site to the support or the diffusion of $\mathrm{H}$ on the support to be ratedetermining. In contrast, the diffusivity of $\mathrm{H}$ on spillover catalysts has been shown to be inversely proportional to the extent of hydrogen coverage. ${ }^{21}$ Those two competing effects might lead to the observation of only a few distinct hydrogen spillover intermediates. Overall, an important finding here 
is that the initial spillover of hydrogen benefits the subsequent activation and spillover of $\mathrm{H}$, i.e., it is a self-catalytic process, which is consistent with the occurrence of an induction period that is sometimes observed for hydrogen spillover. ${ }^{8}$
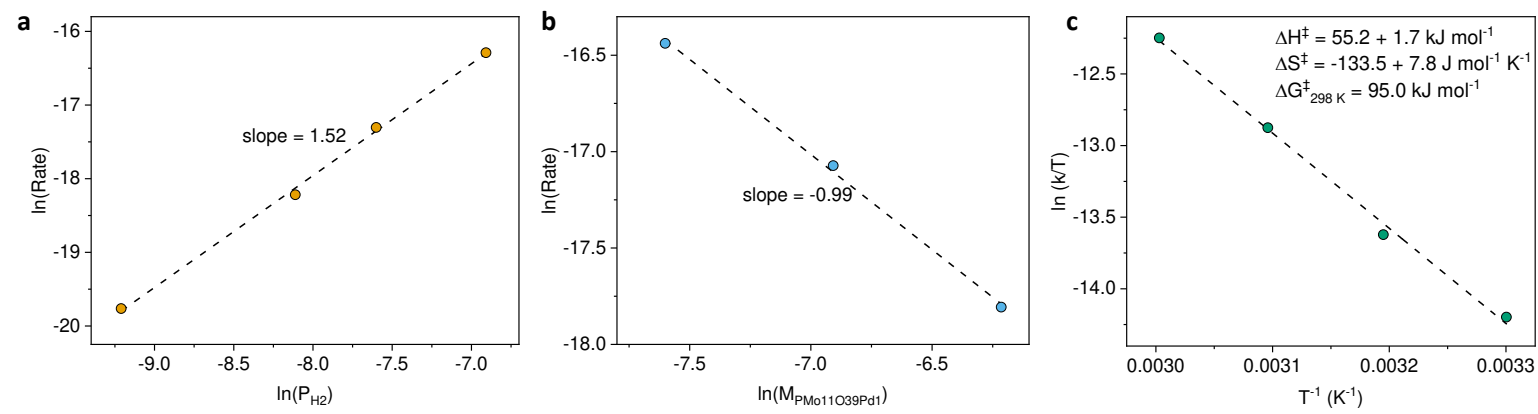

Fig. 2 Kinetics of the hydrogen spillover on $\mathbf{P M o}_{11} \mathbf{O}_{39} \mathbf{P d}_{1}$. Reaction orders towards $\mathbf{a}, \mathrm{H}_{2}$ and $\mathbf{b}$, $\mathrm{PMo}_{11} \mathrm{O}_{39} \mathrm{Pd}_{1}$, during the hydrogen spillover process. c, Eyring plot for the first hydrogen spillover step with the absorbance at $700 \mathrm{~nm}$.

\section{Relation of hydrogen spillover to catalysis:}

To identify the relation of hydrogen spillover to catalysis, we tested the nitrobenzene (NB) hydrogenation during $\mathrm{H}_{2}$ exposure of the catalyst. Remarkably, NB conversion increased in an accelerated manner with time (Fig. 3a). The reaction rate acceleration appeared to follow an approximately two-stage linear behaviour with constants of 0.040 and $0.263 \mathrm{~min}^{-2}$, respectively (Fig. 3b). The inflection point of this increase at around 40 mins coincides well with the onset formation of the final hydrogen spillover species. This led to the hypothesis that spilled over $\mathrm{H}$ on the catalyst has a unique reactivity in the hydrogenation of NB. In order to verify this, we relied on the selective poisoning of Pd species by benzyl mercaptan, a thiol with strong affinity to soft Lewis acids like $\mathrm{Pd}^{2+}$. Adding two equivalents of benzyl mercaptan to $\left\{\left[\mathrm{PMo}_{11} \mathrm{O}_{39} \mathrm{Pd}_{1}-\mathrm{H}_{16}\right]+3 \mathrm{H}^{+}\right\}^{2-}$ after 120 min hydrogen spillover together with the substrate NB in large excess proves that the poisoning protocol is indeed effective in preventing further hydrogen activation and spillover to the support. Still, two NB molecules were converted to aniline per POM equating to the transfer of $12 \mathrm{H}$ atoms to the substrate within 240 min (Fig. 3c). Reaction rates and their changes were further elucidated during catalysis with catalyst poisoning at different time points. Again, for the hydrogenation of NB the conversion increased exponentially without poison while following a strict linear increase after adding benzyl mercaptan. 
The correlated reaction rates are thus increasing linearly for the unpoisoned case while they stayed constant for the case where the poison was added. Noticeably, the reaction rates were dependent on the time point of benzyl mercaptan addition indicating that the extent of spillover affects reaction kinetics (Fig. 3d and Extended Data Fig. 4a). We observed similar trends for the hydrogenation of acetophenone (ACP) with increasing or constant reaction rates when no or two equivalents of benzyl mercaptan were added, respectively (Fig. 3e and Extended Data Fig. 4b). For the hydrogenation of vinyl acetate (VA) comprising an unsaturated $\mathrm{C}=\mathrm{C}$ bond the conversion increased linearly with time and the related reaction rates were constant. Upon addition of benzyl mercaptan, reaction rates immediately dropped to zero and thus the conversion did not increase anymore within $30 \mathrm{~min}$ (Fig. 3f and Extended Data Fig. 4c). This strongly suggests that spilled over $\mathrm{H}$ did not participate in the hydrogenation of $\mathrm{C}=\mathrm{C}$ bonds. Overall, there is a tendency where polar bonds can be hydrogenated by spilled over $\mathrm{H}$ while less polar bonds rely on $\mathrm{H}$ directly from the metal active sites. 

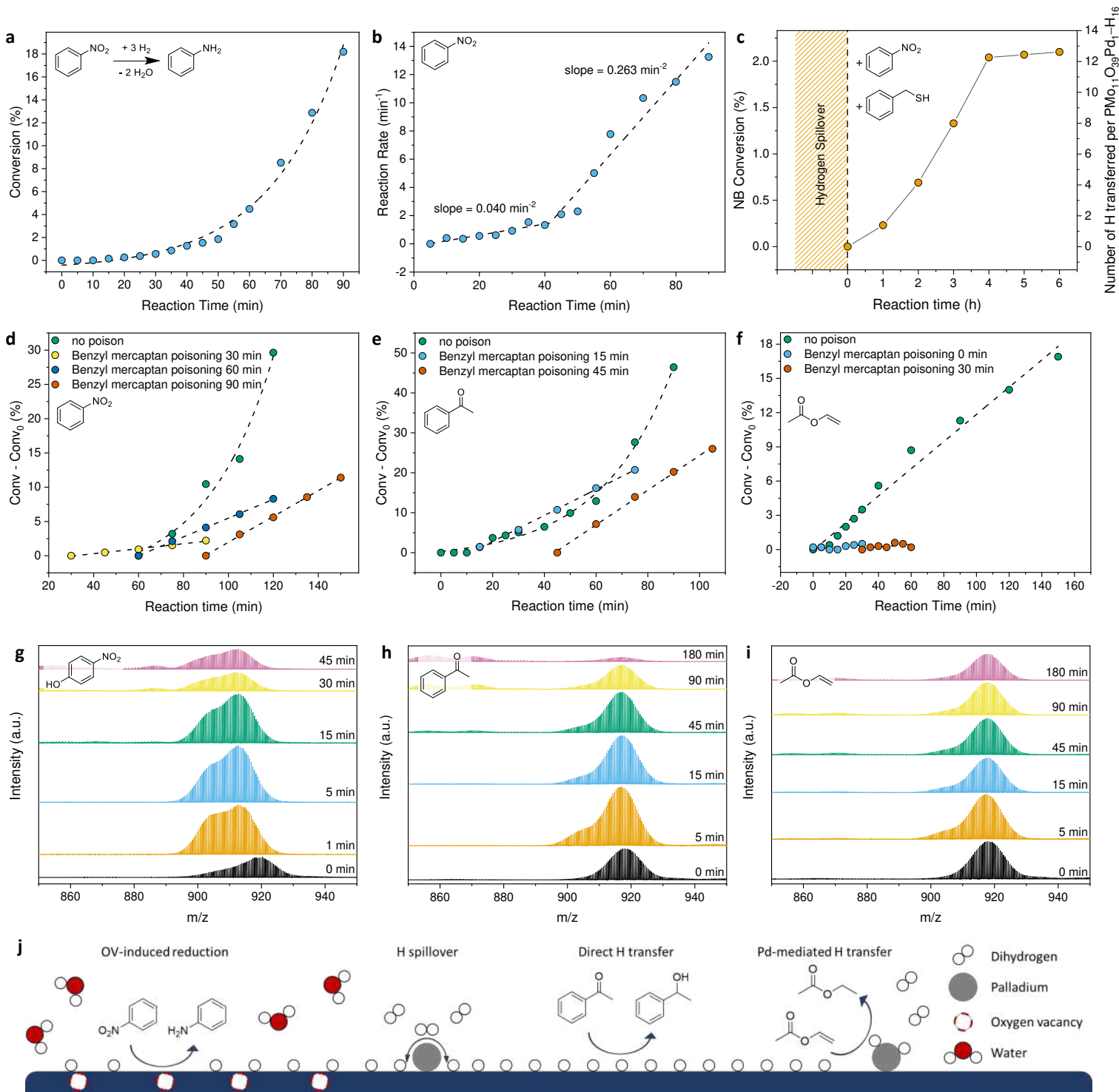

Fig. 3 Hydrogenation kinetics and poisoning studies. a, Conversion and $\mathbf{b}$, reaction rates for the NB hydrogenation during the hydrogen spillover. The slopes (reaction rate acceleration constants in $\mathrm{min}^{-2}$ ) are indicated as slopes of the plot. c, Long-term poisoning study of $\mathrm{PMo}_{11} \mathrm{O}_{39} \mathrm{Pd}_{1}$ during the NB hydrogenation reaction. Reaction kinetics for the hydrogenation of $\mathbf{d}, \mathrm{NB}, \mathbf{e}, \mathrm{ACP}, \mathbf{f}, \mathrm{VA}$ with the addition of 2 equivalents benzyl mercaptan after different reaction times. g-i, ESI-MS during the reaction between $\left\{\left[\mathrm{PMo}_{11} \mathrm{O}_{39} \mathrm{Pd}_{1}-\mathrm{H}_{16}\right]+3 \mathrm{H}^{+}\right\}^{2-}$ and different substrates. $\mathrm{PMo}_{11} \mathrm{O}_{39} \mathrm{Pd}_{1}$ was subjected to $\mathrm{H}_{2}$ for 120 min prior to the addition of 25 equivalents of substrate. $\mathbf{g}, \mathrm{NP}, \mathbf{h}, \mathrm{ACP}, \mathbf{i}, \mathrm{VA}, \mathbf{j}$, Schematic depiction of the contribution of spilled over $\mathrm{H}$ to hydrogenation catalysis for different substrates. Reaction conditions for d-i: V $=0.02 \mathrm{~L}, \mathrm{C}\left(\mathrm{PMo}_{11} \mathrm{O}_{39}{ }^{7-}\right)=1,0.25(\mathbf{c}) \mathrm{mmol} \mathrm{L}^{-1}, \mathrm{C}\left(\mathrm{Pd}^{2+}\right)=0.33,0.08$ (c) $\mathrm{mmol} \mathrm{L}^{-1}, \mathrm{~F}\left(5 \% \mathrm{H}_{2}\right)=40 \mathrm{~cm}^{3} \mathrm{~min}^{-1}, \mathrm{~T}=\mathrm{RT}(\mathbf{a}-\mathbf{d}, \mathbf{g}-\mathbf{i}), 40(\mathbf{e})$, or $0(\mathbf{f}){ }^{\circ} \mathrm{C}, \mathrm{C}$ (substrate) $=8.25 \mathrm{mmol}$ $\mathrm{L}^{-1}$ with the addition of benzyl mercaptan to $\mathrm{C}_{\text {mercaptan }}=0.66,0.17$ (c) $\mathrm{mM}$ after different reaction times ranging from 0 to 90 min.

ESI-MS was used to shed further light on the participation of spilled over $\mathrm{H}$ in the hydrogenation reaction of different substrates. When substrates were added to the catalyst after hydrogen spillover for 
120 min, clear differences were observed among them. For VA, there was no obvious change in the composition of the spilled over catalyst structure within $180 \mathrm{~min}$ (Fig. 3i), confirming that spilled over $\mathrm{H}$ does not participate in $\mathrm{C}=\mathrm{C}$ bond hydrogenation. For $\mathrm{ACP}$, no obvious differences appeared within the first 45 min upon which the intensity of the mass peak for $\left\{\left[\mathrm{PMo}_{11} \mathrm{O}_{39} \mathrm{Pd}_{1}-\mathrm{H}_{16}\right]+3 \mathrm{H}^{+}\right\}^{2-}$ decreased significantly with almost complete $\mathrm{H}$ removal after $180 \mathrm{~min}$ (Fig. 3h). This is consistent with the contribution of spilled over $\mathrm{H}$ to the hydrogenation of $\mathrm{C}=\mathrm{O}$ bonds. The biggest differences arise for the hydrogenation of nitrophenol (NP, it is used to replace NB for its higher solubility) with the immediate removal of $\mathrm{H}$ from the support and the formation of the oxygen vacant species $\left\{\left[\mathrm{PMo}_{11} \mathrm{O}_{38} \mathrm{Pd}_{1}-\mathrm{H}_{4}\right]+\right.$ $\left.3 \mathrm{H}^{+}\right\}^{2-}$ (Fig. 3g). The formation of this intermediate was additionally confirmed by hydrogen spillover experiments in the presence of NP (Supplementary Figs. 8 and 9), while the $\mathrm{H}$ transfer stoichiometry is consistent with the poisoning study discussed earlier (Fig. 3c). Fragmentation of the NP-containing intermediate confirmed the ability of the substrate to refill the oxygen vacancy during reaction (Extended Data Fig. 5). These ESI-MS experiments support the notion that spilled over $\mathrm{H}$ is responsible for the hydrogenation of certain reducible bonds while the exact nature of participation of these $\mathrm{H}$ atoms differs in mechanism between different functional groups (e.g. the direct transfer of $\mathrm{H}$, formation of oxygen vacancies, etc., Fig. 3j). 

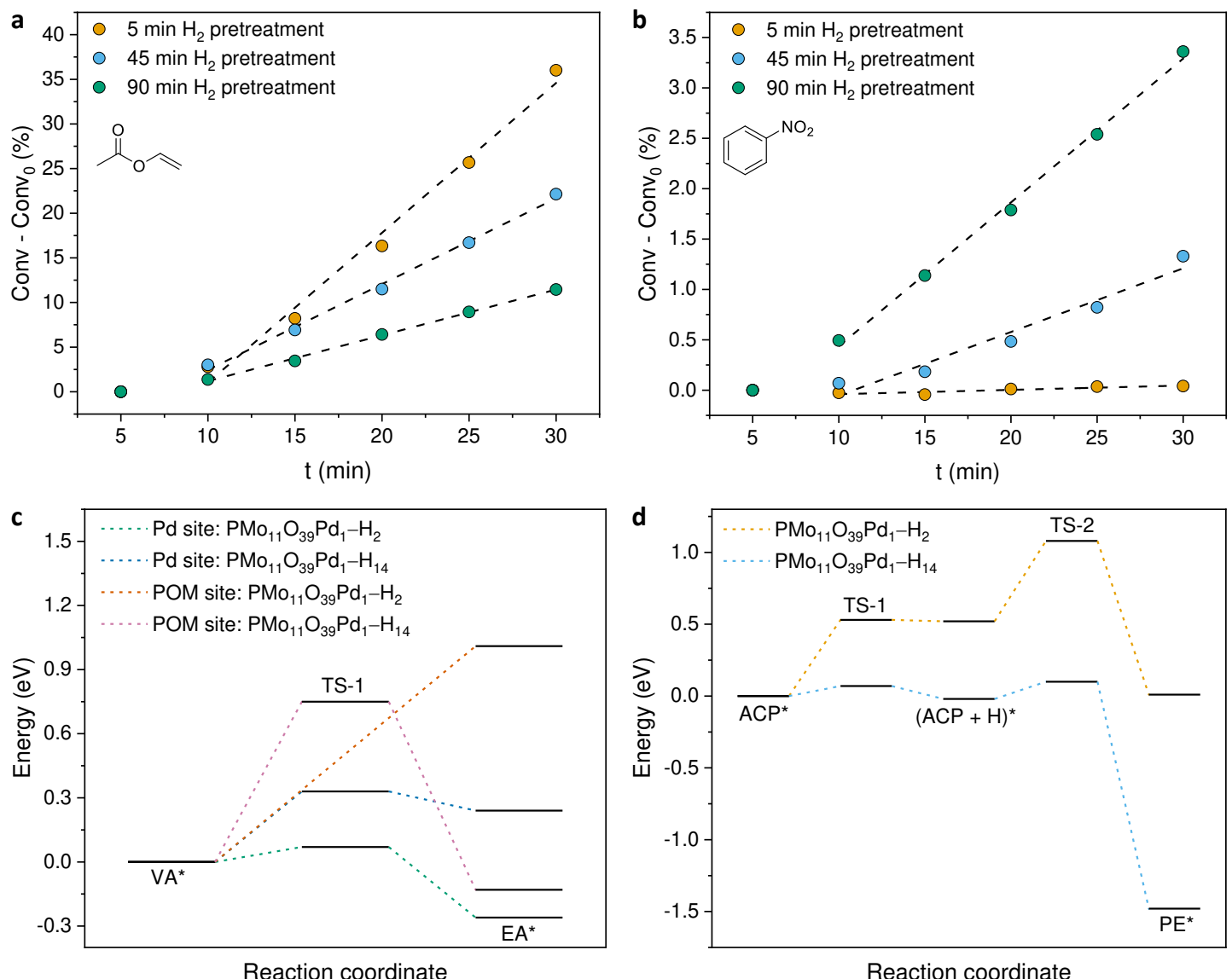

Fig. 4 Correlation between the hydrogen spillover and the hydrogenation activity. Substrate conversion for the a, VA and b, NB hydrogenation after hydrogen spillover for 5, 45, or $90 \mathrm{~min}$. DFT calculated reaction energies for the $\mathbf{c}, \mathrm{VA}$ and $\mathbf{d}$, ACP hydrogenation for different sites on the catalyst and $\mathrm{H}$ coverages. EA stands for ethyl acetate, the hydrogenation product of VA; PE stands for 1phenylethanol, the hydrogenation product of ACP.

We measured the initial hydrogenation turnover frequencies for NB and VA with $\mathrm{PMo}_{11} \mathrm{O}_{39} \mathrm{Pd}_{1}$ after different times of $\mathrm{H}_{2}$ exposure to obtain a clearer correlation between the extent of hydrogen spillover and the hydrogenation kinetics. A 33-fold increase in NB hydrogenation activity after 90 min initial hydrogen exposure was observed (Fig. 4b). In sharp contrast, the reaction rate dropped by a factor of 3.3 after $90 \mathrm{~min}_{2}$ exposure of the catalyst for VA hydrogenation (Fig. 4a). This indicates that not only does hydrogen spillover contribute to the hydrogenation of various reducible groups differently, but also can hydrogen spillover be detrimental to catalysis in some cases.

Since experimental data provide compelling evidence that hydrogenation may occur both on the POM support through spilled over hydrogen and on the metal site through Pd-mediated hydrogen transfer, 
the reaction energies of the VA and ACP hydrogenation over two types of sites located on the support and on Pd under different hydrogen coverages were calculated by DFT. For the hydrogenation of VA, only the Pd site showed reasonably low reaction barriers with marked effects of the $\mathrm{H}$ coverage on both kinetics and thermodynamics of the reaction. Activation energies are thus $0.07 \mathrm{eV}$ and $0.33 \mathrm{eV}$ for low and high $\mathrm{H}$ coverages, respectively (Fig. 4c and Extended Data Fig. 6). In contrast, the hydrogenation of polar bonds such as $\mathrm{C}=\mathrm{O}$ in $\mathrm{ACP}$ only proceeds with low activation barriers when a catalyst contains a high $\mathrm{H}$ coverage. Low hydrogen coverages increase the reaction barriers and render the hydrogenation far less exothermic (Fig. 4d and Extended Data Fig. 7). In addition, the local $\mathrm{H}$ density, depending on the location of $\mathrm{H}$ atoms, significantly impacted the hydrogenation reaction barriers (Supplementary Fig. 10). The hydrogenation of NB should be assumed to depend on the extent of hydrogen spillover as well, since the proclivity for forming oxygen vacancies is $\mathrm{H}$ coverage-dependent (Supplementary Table 2). Kinetic barriers for the deoxygenation of ACP are high on Mo POM-based Pd SACs, in accordance with one of our previous studies (Supplementary Fig. 11). ${ }^{22}$

\section{Implications for conventional $\mathbf{H}$ spillover catalysts:}

To verify whether the findings related to hydrogen spillover are specific to POM-supported SACs or more generally applicable, we performed analogous investigations on the archetypical hydrogen spillover catalyst $\mathrm{Pt} / \mathrm{WO}_{3}$, which undergoes a colour change from yellow to blue from this process (Extended Data Fig. 8). Plotting the initial reaction rates for the VA and ACP hydrogenation reaction against time after different durations of $\mathrm{H}_{2}$ treatment reveal a picture comparable to the case of $\mathrm{PMo}_{11} \mathrm{O}_{39} \mathrm{Pd}_{1}$. Hydrogenation rates drop by a factor of 7.8 for $\mathrm{VA}$ when $\mathrm{Pt} / \mathrm{WO}_{3}$ was exposed to $\mathrm{H}_{2}$ for 90 min while the opposite is true for NB with a rate increase by a factor of 3.6 (Figs. 5a, b). Thus, spilled over $\mathrm{H}$ positively contributes to NB reduction while hinders VA hydrogenation. Further verification of this hypothesis was obtained from isotope labelling experiments. Provided that the spilled over $\mathrm{H}$ exchanges protons with protic solvents and considering that the rate of hydrogen spillover is considerably larger than its reversal, differences in the $\mathrm{D}$ incorporation should be expected when $\mathrm{D}_{2} \mathrm{O}$ and $\mathrm{H}_{2}$ are used during the hydrogenation reaction. Indeed, significant deuteration of the ACP hydrogenation product 1-phenylethanol was observed while the D incorporation was negligible when 
VA was used as substrate (Figs. 5c, d). This strongly supports the assumption that H/D from the support is involved in the hydrogenation of the polar $\mathrm{C}=\mathrm{O}$ bond while only $\mathrm{H}$ from the $\mathrm{Pt}$ nanoparticles are transferred to VA.
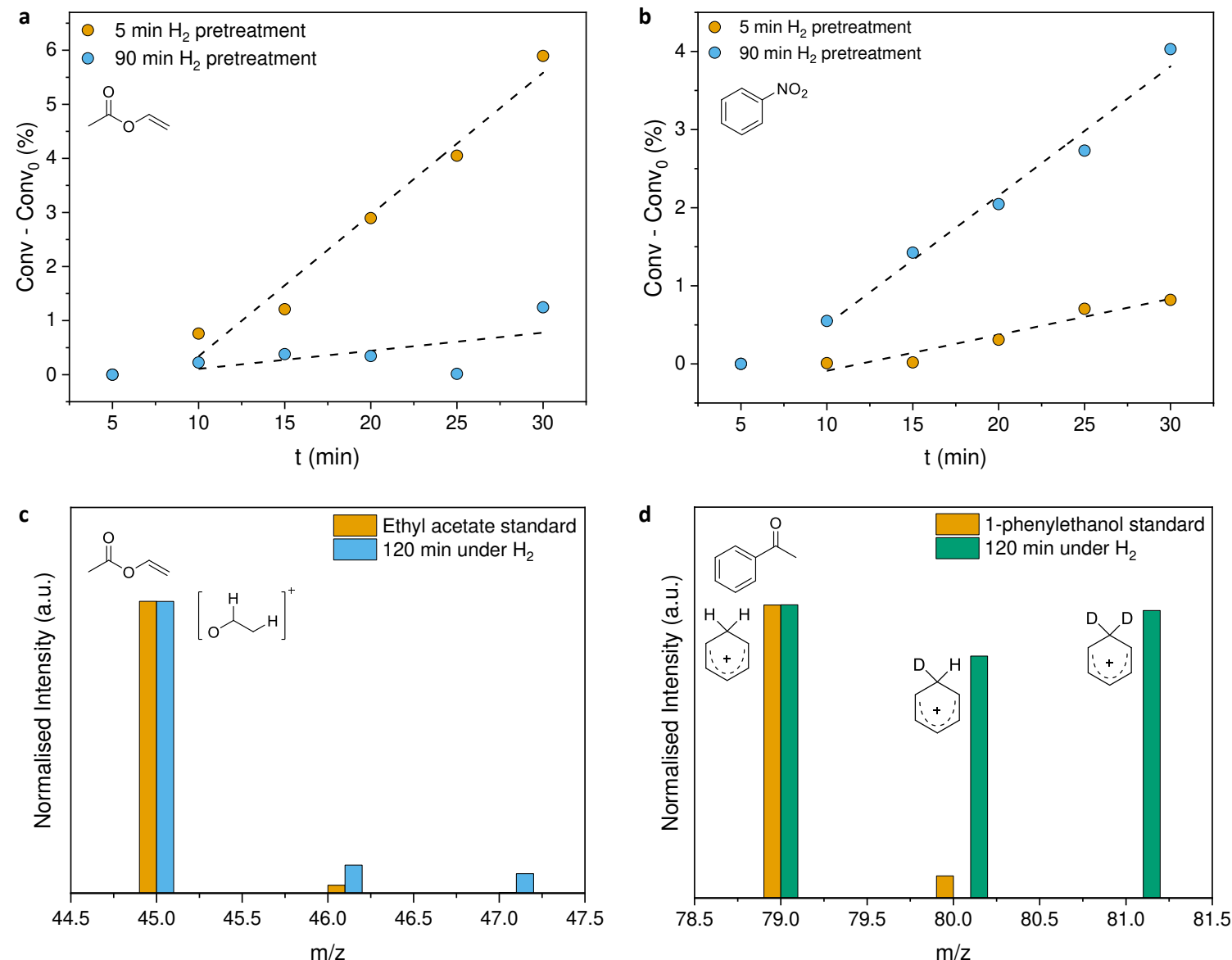

Fig. 5 | Correlation between hydrogen spillover and the hydrogenation activity on Pt/WO 3 . Substrate conversion for the hydrogenation of $\mathbf{a}$, VA and $\mathbf{b}$, NB after hydrogen spillover for 5 or 90 min. Deuterium isotope-labelling during the hydrogenation of $\mathbf{c}, \mathrm{VA}$ and $\mathbf{d}, \mathrm{ACP}$ in $\mathrm{D}_{2} \mathrm{O}$ as solvent after treatment with $\mathrm{H}_{2}$ as reductant for $120 \mathrm{~min}$. The MS spectra of standard samples of the reaction products are shown for comparison.

Studies on bimetallic single-atom alloys have revealed certain factors affecting spillover catalysis but the nature of $\mathrm{H}$ on metallic surfaces is very different compared to more conventionally investigated metal oxides. ${ }^{5,23,24}$ Understanding the impact of hydrogen spillover on the electronic structure of the catalyst as well as its hydrogenation activity might have implications for reactions that do not involve $\mathrm{H}$ atom transfer directly but which may either form $\mathrm{H}$ species as side-product or benefit from the cofeeding of $\mathrm{H}_{2}$ such as shown recently for epoxidation reactions. ${ }^{25}$ For reactions like the $\mathrm{CO}_{2}$ or $\mathrm{N}_{2}$ 
hydrogenation, the contribution of hydrogen spillover to catalysis has been vividly discussed recently. ${ }^{26-}$ ${ }^{29}$ Based on our results, it is very likely that hydrogen spillover plays a crucial role in forming oxygen vacancies and transferring $\mathrm{H}$ to polar molecules like $\mathrm{CO}_{2}$. Care should be taken for correlating hydrogen spillover and enhanced catalytic activity since in some cases limiting the spillover of $\mathrm{H}$ on the support appears to be beneficial. We developed a related heterogeneous single-atom catalyst and observed comparable hydrogen spillover behaviour as well as hydrogenation kinetics for solid-gas biphasic processes and we intend to communicate those data soon.

\section{Conclusions}

In summary, the unique soluble SAC-POM catalyst system allows for the investigation of hydrogen spillover to a previously unattainable level of detail. Our observations based on kinetics, spectroscopy, spectrometry, and DFT calculations reveal that hydrogen spillover is an autocatalytic process, that the spilled over $\mathrm{H}$ on metal oxides is highly protonic in nature and induces vacancy formation on the support, and that the maximum $\mathrm{H}$ coverage is determined by thermodynamic limitations. The nature of the contribution of spilled over $\mathrm{H}$ to catalysis depends on the reducible functional group: for nitro group and $\mathrm{C}=\mathrm{O}$ bond hydrogenation spilled over hydrogen enhances the reaction by direct participation from the support and may additionally decrease the reaction barrier on the metal site; for $\mathrm{C}=\mathrm{C}$ bond hydrogenation, in stark contrast, spilled over hydrogen can not be directly added to the double bond while their presence increases the hydrogenation barrier on the metal site, thus decelerates the reaction. Comparable experiments performed on $\mathrm{Pt} / \mathrm{WO}_{3}$ support the notion that the conclusions drawn from the POM-based SAC are applicable for catalysts which exhibit hydrogen spillover in general. This study provides fundamental insights as well as guidance for designing improved hydrogenation catalysts targeted for various substrates. It may also inspire more studies of complex catalytic phenomena on model catalyst systems comprising single-atom sites..$^{30-37}$

\section{Author contributions}

M.J.H. performed the experiments and analysed the data, V.F. did the DFT calculations. N.Y. conceived and supervised the project. All authors contributed to writing the manuscript. 


\section{Competing interests}

The authors declare no competing interest.

\section{Acknowledgements}

M.J.H. acknowledges the SINGA scholarship for financing his PhD studies. Part of this work was performed at the Center for Nanophase Materials Sciences, a US Department of Energy Office of Science User Facility.

\section{Data availability}

All relevant data supporting our findings are provided in the main text and Supplementary Information.

\section{References}

1 Prins, R. Hydrogen Spillover. Facts and Fiction. Chem. Rev. 112, 2714-2738, (2012).

2 Roland, U., Braunschweig, T. \& Roessner, F. On the nature of spilt-over hydrogen. J. Mol. Catal. A Chem. 127, 61-84, (1997).

3 Doudin, N. et al. Understanding Heterolytic $\mathrm{H}_{2}$ Cleavage and Water-Assisted Hydrogen Spillover on $\mathrm{Fe}_{3} \mathrm{O}_{4}$ (001)-Supported Single Palladium Atoms. ACS Catal. 9, 7876-7887, (2019).

4 Liu, J. et al. Developing Single-Site Pt Catalysts for the Preferential Oxidation of CO: A Surface Science and First Principles-Guided Approach. Appl. Catal. B, 119716, (2020).

5 Jiang, L. et al. Facet engineering accelerates spillover hydrogenation on highly diluted metal nanocatalysts. Nat. Nanotechnol. 15, 848-853, (2020).

6 Fung, V., Hu, G., Wu, Z. \& Jiang, D.-e. Hydrogen in Nanocatalysis. J. Phys. Chem. Lett. 11, 7049-7057, (2020).

7 Im, J., Shin, H., Jang, H., Kim, H. \& Choi, M. Maximizing the catalytic function of hydrogen spillover in platinum-encapsulated aluminosilicates with controlled nanostructures. Nat. Commun. 5, 3370, (2014).

8 Sermon, P. A. \& Bond, G. C. Studies of hydrogen spillover. Part 1.-Study of the rate, extent and products of hydrogen spillover from platinum to the trioxides of tungsten and molybdenum. J. Chem. Soc., Faraday Trans. 1 72, 730-744, (1976).

9 Sermon, P. A. \& Bond, G. C. Studies of hydrogen spillover. Part 2.-Titration of hydrogen adsorbed upon silica supported platinum by pent-1-ene. J. Chem. Soc., Faraday Trans. 1 72, 745-754, (1976).

10 Mitchell, P. C. H., Ramirez-Cuesta, A. J., Parker, S. F., Tomkinson, J. \& Thompsett, D. Hydrogen Spillover on Carbon-Supported Metal Catalysts Studied by Inelastic Neutron Scattering. Surface Vibrational States and Hydrogen Riding Modes. J. Phys. Chem. B 107, 6838-6845, (2003).

11 Lykhach, Y. et al. Hydrogen spillover monitored by resonant photoemission spectroscopy. J. Catal. 285, 6-9, (2012).

12 Karim, W. et al. Catalyst support effects on hydrogen spillover. Nature 541, 68-71, (2017).

13 Zhang, B. et al. Stabilizing a Platinum ${ }_{1}$ Single-Atom Catalyst on Supported Phosphomolybdic Acid without Compromising Hydrogenation Activity. Angew. Chem. Int. Ed. 55, 8319-8323, (2016). 
14 Hülsey, M. J. et al. In situ spectroscopy-guided engineering of rhodium single-atom catalysts for CO oxidation. Nat. Commun. 10, 1330, (2019).

15 Zhang, B. et al. Atomically Dispersed Pt ${ }_{1}$-Polyoxometalate Catalysts: How Does MetalSupport Interaction Affect Stability and Hydrogenation Activity? J. Am. Chem. Soc. 141, 8185-8197, (2019).

16 Hülsey, M. J., Sun, G., Sautet, P. \& Yan, N. Observing single-atom catalytic sites during reactions with electrospray ionisation mass spectrometry. Angew. Chem. Int. Ed. 60, 4764-4773, (2021).

17 Chen, J., Liu, S., Feng, W., Zhang, G. \& Yang, F. Fabrication phosphomolybdic acid-reduced graphene oxide nanocomposite by UV photo-reduction and its electrochemical properties. Phys. Chem. Chem. Phys. 15, 5664-5669, (2013).

18 Ohisa, S. et al. Post-Treatment-Free Solution-Processed Reduced Phosphomolybdic Acid Containing Molybdenum Oxide Units for Efficient Hole-Injection Layers in Organic LightEmitting Devices. Inorg. Chem. 57, 1950-1957, (2018).

19 Goulas, K. A., Mironenko, A. V., Jenness, G. R., Mazal, T. \& Vlachos, D. G. Fundamentals of C-O bond activation on metal oxide catalysts. Nat. Catal. 2, 269-276, (2019).

$20 \mathrm{Fu}$, J. et al. C-O bond activation using ultralow loading of noble metal catalysts on moderately reducible oxides. Nat. Catal. 3, 446-453, (2020).

21 Li, Y., Yang, F. H. \& Yang, R. T. Kinetics and Mechanistic Model for Hydrogen Spillover on Bridged Metal-Organic Frameworks. J. Phys. Chem. C 111, 3405-3411, (2007).

22 Hülsey, M. J. et al. Zero-Valent Pd Atoms Anchored on Polyoxometalate for Low Temperature Hydrodeoxygenation. ChemRXiv, (2020).

23 Kyriakou, G. et al. Isolated Metal Atom Geometries as a Strategy for Selective Heterogeneous Hydrogenations. Science 335, 1209-1212, (2012).

24 Marcinkowski, M. D. et al. Controlling a spillover pathway with the molecular cork effect. Nat. Mater. 12, 523-528, (2013).

25 Xiong, M. et al. In situ tuning of electronic structure of catalysts using controllable hydrogen spillover for enhanced selectivity. Nat. Commun. 11, 4773, (2020).

26 Jung, K.-D. \& Bell, A. T. Role of hydrogen spillover in methanol synthesis over $\mathrm{Cu} / \mathrm{ZrO}_{2}$. J. Catal. 193, 207-223, (2000).

27 Mao, C. et al. Hydrogen Spillover to Oxygen Vacancy of $\mathrm{TiO}_{2-\mathrm{x}} \mathrm{H}_{\mathrm{y}} / \mathrm{Fe}$ : Breaking the Scaling Relationship of Ammonia Synthesis. J. Am. Chem. Soc. 142, 17403-17412, (2020).

28 Wang, C. et al. Product Selectivity Controlled by Nanoporous Environments in Zeolite Crystals Enveloping Rhodium Nanoparticle Catalysts for $\mathrm{CO}_{2}$ Hydrogenation. J. Am. Chem. Soc. 141, 8482-8488, (2019).

29 Rui, N. et al. Hydrogenation of $\mathrm{CO}_{2}$ to Methanol on a $\mathrm{Au}^{\delta+}-\mathrm{In}_{2} \mathrm{O}_{3-\mathrm{x}}$ Catalyst. ACS Catal. 10, 11307-11317, (2020).

30 Chen, F., Jiang, X., Zhang, L., Lang, R. \& Qiao, B. Single-atom catalysis: Bridging the homoand heterogeneous catalysis. Chin. J. Catal. 39, 893-898, (2018).

31 Conner, W. C. \& Falconer, J. L. Spillover in Heterogeneous Catalysis. Chem. Rev. 95, 759788, (1995).

32 Zhang, H. et al. Computational and experimental demonstrations of one-pot tandem catalysis for electrochemical carbon dioxide reduction to methane. Nat. Commun. 10, 3340, (2019).

33 Gao, J. et al. Selective C-C Coupling in Carbon Dioxide Electroreduction via Efficient Spillover of Intermediates As Supported by Operando Raman Spectroscopy. J. Am. Chem. Soc. 141, 18704-18714, (2019).

34 DeRita, L. et al. Structural evolution of atomically dispersed Pt catalysts dictates reactivity. Nat. Mater. 18, 746-751, (2019).

35 DeRita, L. et al. Catalyst Architecture for Stable Single Atom Dispersion Enables SiteSpecific Spectroscopic and Reactivity Measurements of CO Adsorbed to Pt Atoms, Oxidized Pt Clusters, and Metallic Pt Clusters on $\mathrm{TiO}_{2}$. J. Am. Chem. Soc. 139, 1415014165, (2017). 
36 Liu, R. \& Streb, C. Polyoxometalate-Single Atom Catalysts (POM-SACs) in Energy Research and Catalysis. Adv. Energy Mater., 2101120, (2021).

37 Zhang, X. et al. A stable low-temperature H2-production catalyst by crowding Pt on $\alpha$ MoC. Nature 589, 396-401, (2021).

38 Kresse, G. \& Furthmuller, J. Efficiency of Ab-Initio Total Energy Calculations for Metals and Semiconductors Using a Plane-Wave Basis Set. Comput. Mater. Sci. 6, 15-50, (1996).

39 Kresse, G. \& Furthmuller, J. Efficient Iterative Schemes for Ab Initio Total-Energy Calculations Using a Plane-Wave Basis Set. Phys. Rev. B 54, 11169-11186, (1996).

40 Perdew, J. P., Burke, K. \& Ernzerhof, M. Generalized Gradient Approximation Made Simple. Phys. Rev. Lett. 77, 3865-3868, (1996).

41 Blöchl, P. E. Projector Augmented-Wave Method. Phys. Rev. B 50, 17953-17979, (1994).

42 Henkelman, G., Uberuaga, B. P. \& Jónsson, H. A Climbing Image Nudged Elastic Band Method for Finding Saddle Points And Minimum Energy Paths. J. Chem. Phys. 113, $9901-$ 9904, (2000). 


\section{Methods}

\section{Catalyst synthesis}

The lacunary POMs were synthesised according to previously published procedures. ${ }^{16}$ For $\mathrm{K}_{7} \mathrm{PW}_{11} \mathrm{O}_{39}$, in short, $18.15 \mathrm{~g}$ sodium tungstate dihydrate (SCR), $5 \mathrm{~mL}$ phosphoric acid (VWR, reagent grade) and $8.8 \mathrm{~mL}$ glacial acetic acid (Merck, reagent grade) dissolved in $30 \mathrm{~mL}$ deionised water and heated to reflux for 120 min. After the mixture was cooled down, $6 \mathrm{~g}$ potassium chloride (Sigma Aldrich, ACS reagent) were added, and the precipitation was continued for $60 \mathrm{~min}$ at room temperature. The obtained solid was separated by filtration and washed three times with small amounts of hot deionised water. Product purity was improved by recrystallisation in $5 \mathrm{~mL}$ deionised water with $1 \mathrm{~g}$ potassium chloride. This reprecipitation procedure was repeated three times and the final solid was dried at $95{ }^{\circ} \mathrm{C}$ overnight. SACs were synthesised in situ by mixing appropriate amounts of $\mathrm{K}_{7} \mathrm{PW}_{11} \mathrm{O}_{39}$ and metal nitrate salt. $\mathrm{PMo}_{11} \mathrm{O}_{39}{ }^{7-}$ solutions were prepared fresh before each reaction. $40 \mathrm{mg}$ phosphomolybdic acid hydrate (Sigma Aldrich, ACS reagent) were dissolved in $15 \mathrm{~mL}$ deionised water and the $\mathrm{pH}$ was adjusted to 4.3 with a $1 \mathrm{~mol} \mathrm{~L}^{-1}$ solution of lithium carbonate (Sigma Aldrich, ACS reagent) with an accumet AB150 $\mathrm{pH}$ meter. Appropriate amounts of metal nitrate salt were added, and the $\mathrm{pH}$ was again adjusted to 4.3 with $1 \mathrm{~mol} \mathrm{~L}^{-1}$ lithium carbonate solution. The total volume was finally adjusted to $20 \mathrm{~mL}$. Transition metal salts used in this study were platinum nitrate (Alfa Aesar, 15\% Pt solution), palladium nitrate hydrate (Sigma Aldrich), and rhodium nitrate (Sigma Aldrich, 10\% Rh solution).

$1 \mathrm{wt} \% \mathrm{Pt} / \mathrm{WO}_{3}$ catalysts were synthesised by incipient wetness impregnation. $26 \mathrm{mg}$ chloroplatinic acid (Sigma Aldrich, ACS reagent) were dissolved in $150 \mu \mathrm{L}$ deionised water and slowly added to $1.0 \mathrm{~g}$ $\mathrm{WO}_{3}$ (Sigma Aldrich). The resulting mixture was sonicated for $10 \mathrm{~min}$ and then dried overnight at 95 ${ }^{\circ} \mathrm{C}$.

\section{Catalyst testing}

The hydrogenation of nitrobenzene (Sigma Aldrich, 99\%), acetophenone (Sigma Aldrich, 99\%), and vinyl acetate (Sigma Aldrich, with 3-20 ppm hydroquinone as inhibitor, $\geq 99 \%$ ) was conducted. Appropriate amounts of substrate were added to aqueous solutions of the in situ formed catalysts. After 
mixing for 1-2 min, the flow of $40 \mathrm{~mL} \mathrm{~min}^{-1} 5 \% \mathrm{H}_{2}$ (AirLiquide, balance $\mathrm{N}_{2}$ ) was started. $300 \mu \mathrm{L}$ samples were taken after regular time intervals, and the reaction solution aliquots were extracted with $300 \mu \mathrm{L}$ ethyl acetate (VWR, HPLC grade), or $300 \mu \mathrm{L}$ butyl formate (Sigma Aldrich, 97\%) in the case of vinyl acetate as reactant. The organic fractions were subjected to gas chromatography (GC, Agilent 7890 A) equipped with an SGE 054199 column and a flame ionisation detector (FID).

Catalytic experiments with $\mathrm{Pt} / \mathrm{WO}_{3}$ were performed in a very similar fashion. 25-50 mg catalyst, $40 \mathrm{~mL}$ deionised water and substrate were mixed under $5 \% \mathrm{H}_{2}$ at a flow rate of $40 \mathrm{~mL} \mathrm{~min}^{-1}$. The mixture was stirred at $1500 \mathrm{rpm}$ during reaction to avoid mass transfer limitations. The liquid-liquid extraction procedure before analysis was performed analogous to the reactions with the solubilised SAC. For the isotope labelling experiments, $50 \mathrm{mg} \mathrm{Pt} / \mathrm{WO}_{3}, 2 \mathrm{~mL} \mathrm{D}_{2} \mathrm{O}$ (Cambridge Isotope Labs, 99.8\% D labelling), and certain amounts of substrate were mixed. $5 \% \mathrm{H}_{2}$ at a flow rate of $40 \mathrm{~mL} \mathrm{~min}^{-1}$ was applied under stirring at $1500 \mathrm{rpm}$. In addition to GC-FID analysis, a GC (Agilent 7890A) equipped with an HP-5 capillary column and an Agilent 5975C inert MSD with Triple Axis Detector was used for product identification.

For poisoning experiments, appropriate amounts of benzyl mercaptan (Sigma Aldrich, 99\%) were added into the reaction solution at various time points and samples were taken at specific time intervals and extracted by organic solvent. For the long-term poisoning study, the hydrogen spillover on $\mathrm{PMo}_{11} \mathrm{O}_{39} \mathrm{Pd}_{1}$ was performed for 120 min under usual conditions, upon which both benzyl mercaptan and nitrobenzene were added.

\section{DFT calculations}

Density functional theory (DFT) calculations were performed with the Vienna ab initio Simulation Package (VASP). ${ }^{38,39}$ The Perdew-Burke-Ernzerhof $(\mathrm{PBE})^{40}$ functional form of generalized-gradient approximation (GGA) for electron exchange and correlation energies were used. Spin polarization was considered for all calculations. The projector-augmented wave method was used to describe the electron-core interaction ${ }^{38,41}$ with a kinetic energy cutoff of $450 \mathrm{eV}$. A cubic cell with cell lengths of 20 $\AA$ was used to ensure a sufficient distance between images. Geometry optimizations were performed to 
a force convergence of $0.02 \mathrm{eV} / \AA$. Transition states (TS) were obtained with the nudged elastic band $(\mathrm{NEB})^{42}$ method using a force convergence criterion of $0.05 \mathrm{eV} / \mathrm{A}$.
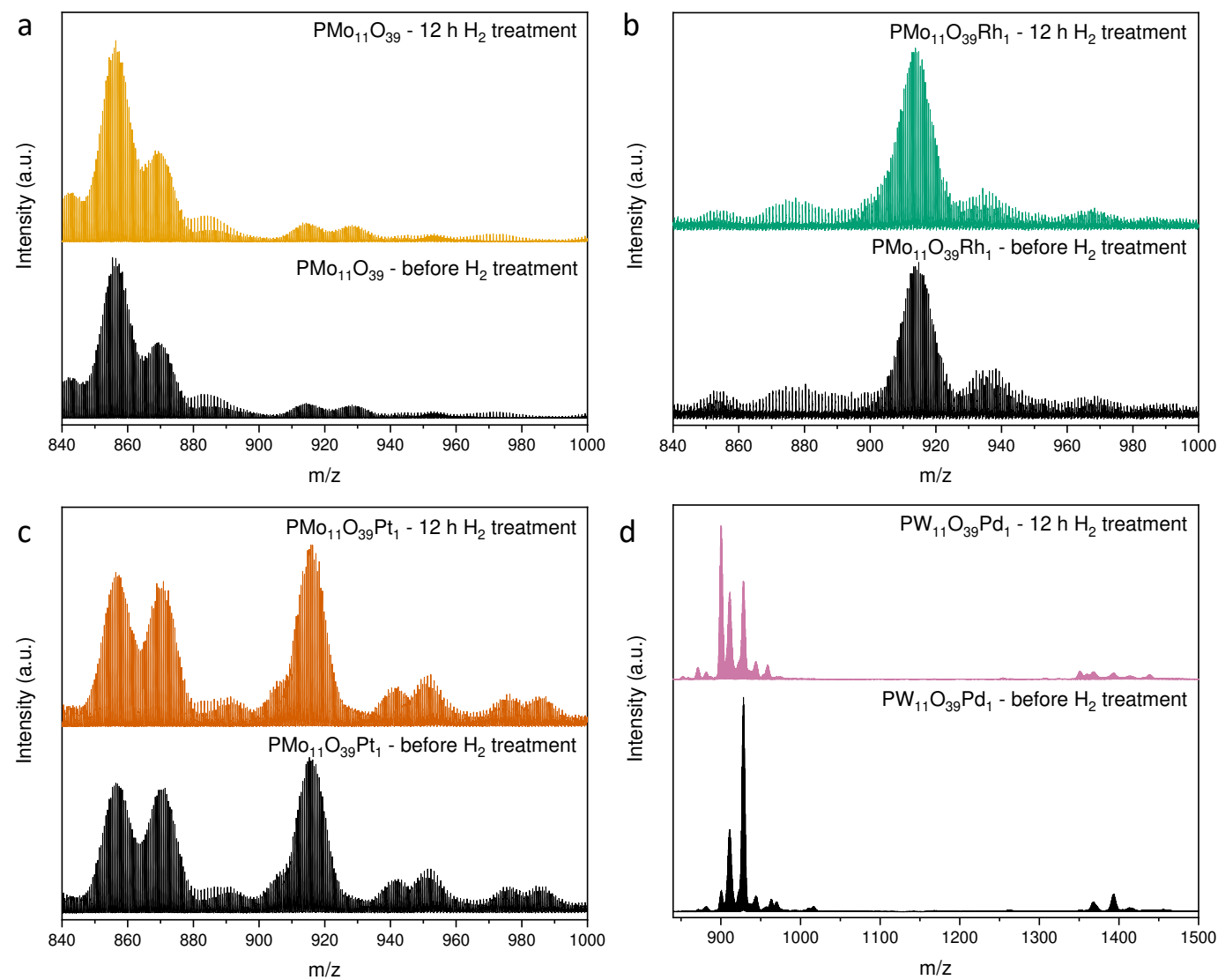

Extended Data Fig. 1 | ESI-MS of different $\mathrm{M}_{1}$-POM combinations before and after 12 h $\mathbf{H}_{2}$ exposure. Reaction conditions: $\mathrm{V}_{\text {total }}=0.02 \mathrm{~L}$ deionised water with $\mathrm{C}_{\mathrm{PM} 11039}=1 \mathrm{mM}, \mathrm{C}_{\mathrm{M}}=0.5 \mathrm{mM}$, $\mathrm{F}\left(5 \% \mathrm{H}_{2} / \mathrm{N}_{2}\right)=40 \mathrm{~cm}^{3} \mathrm{~min}^{-1}, \mathrm{~T}=\mathrm{RT}$. a, $\mathrm{PMo}_{11} \mathrm{O}_{39}, \mathbf{b}, \mathrm{PMo}_{11} \mathrm{O}_{39} \mathrm{Rh}_{1}, \mathbf{c}, \mathrm{PMo}_{11} \mathrm{O}_{39} \mathrm{Pt}_{1}, \mathbf{d}, \mathrm{PW}_{11} \mathrm{O}_{39} \mathrm{Pd}_{1}$. 


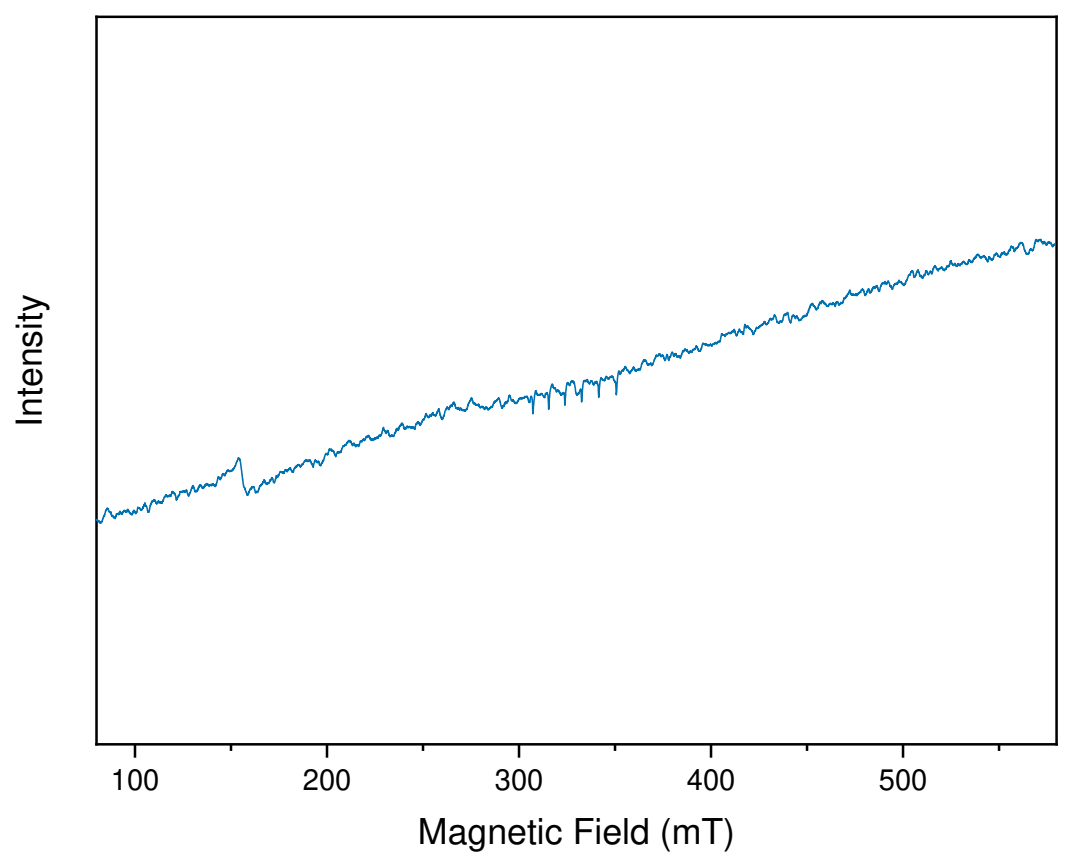

Extended Data Fig. 2 | EPR spectrum of $\mathrm{PMo}_{11} \mathrm{O}_{39} \mathrm{Pd}_{1}$ after $\mathrm{H}_{2}$ exposure for $90 \mathrm{~min}$. $\mathrm{Mn}^{2+}$ ions were added as internal reference and the typical hexet can be observed centred at around $330 \mathrm{mT}$. Otherwise $\mathrm{PMo}_{11} \mathrm{O}_{39} \mathrm{Pd}_{1}$ after hydrogen spillover for $90 \mathrm{~min}$ is completely EPR silent. Reaction conditions: $\mathrm{V}_{\text {total }}=0.02 \mathrm{~L}$ deionised water with $\mathrm{C}_{\mathrm{PMo1} 1039}=10 \mathrm{mM}, \mathrm{C}_{\mathrm{Pd}}=5 \mathrm{mM}, \mathrm{F}\left(5 \% \mathrm{H}_{2} / \mathrm{N}_{2}\right)=40$ $\mathrm{cm}^{3} \min ^{-1}, \mathrm{t}=90 \mathrm{~min}, \mathrm{~T}=\mathrm{RT}$. 


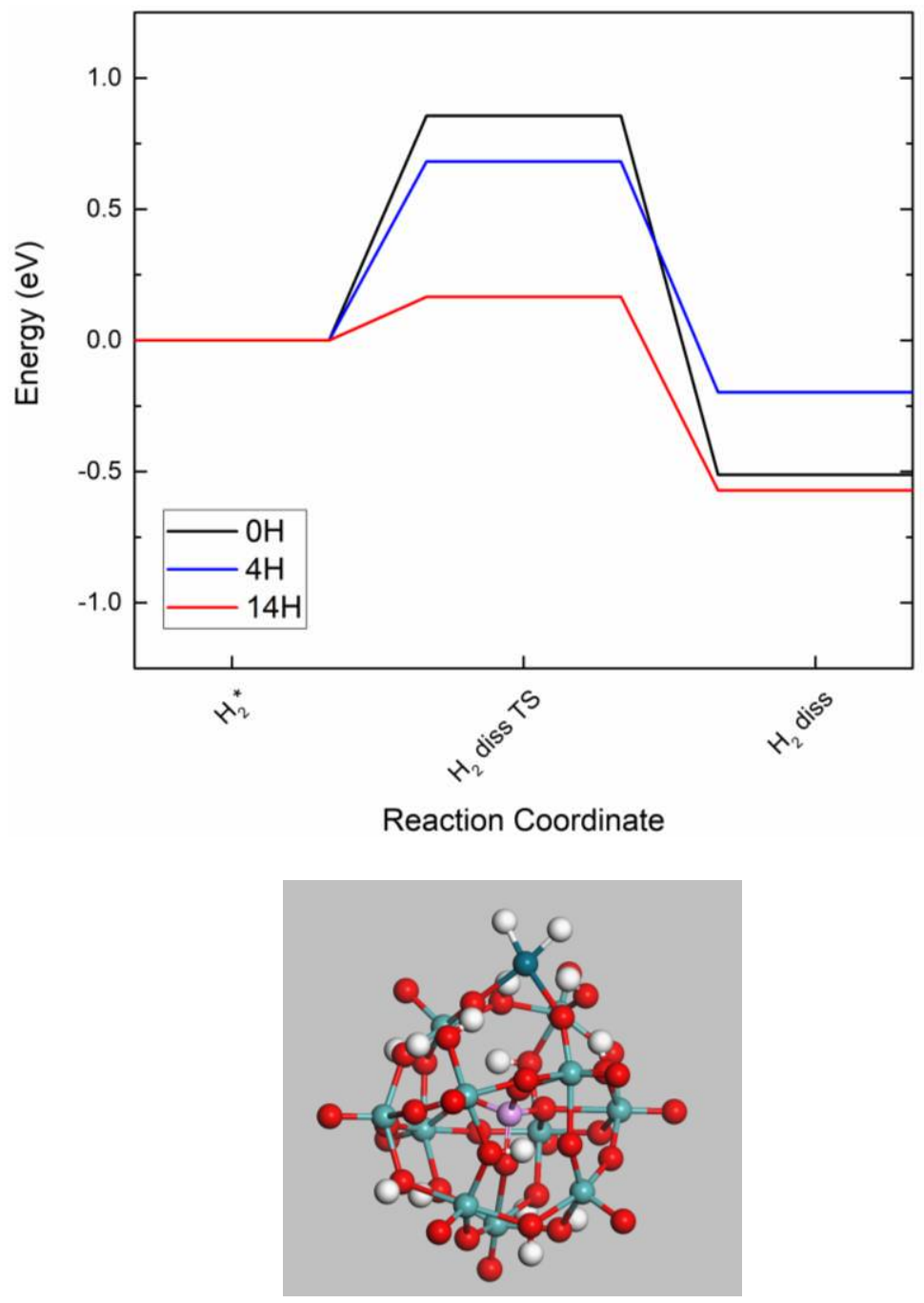

Extended Data Fig. 3 | DFT-calculated hydrogen spillover energy barriers on $\mathbf{P M o}_{11} \mathrm{O}_{39} \mathbf{P d}_{1}$ as a function of $\mathbf{H}$ coverage. In the bottom, the structure after the homolytic splitting of $\mathrm{H}_{2}$ on the $\mathrm{Pd}$ site for the $\mathrm{PMo}_{11} \mathrm{O}_{39} \mathrm{Pd}_{1}$ catalyst with $14 \mathrm{H}$ atoms is shown. After that, the $\mathrm{H}_{2}$ splitting results in the formation of oxygen vacancies, consistent with experimental observations (Fig. 1b). 

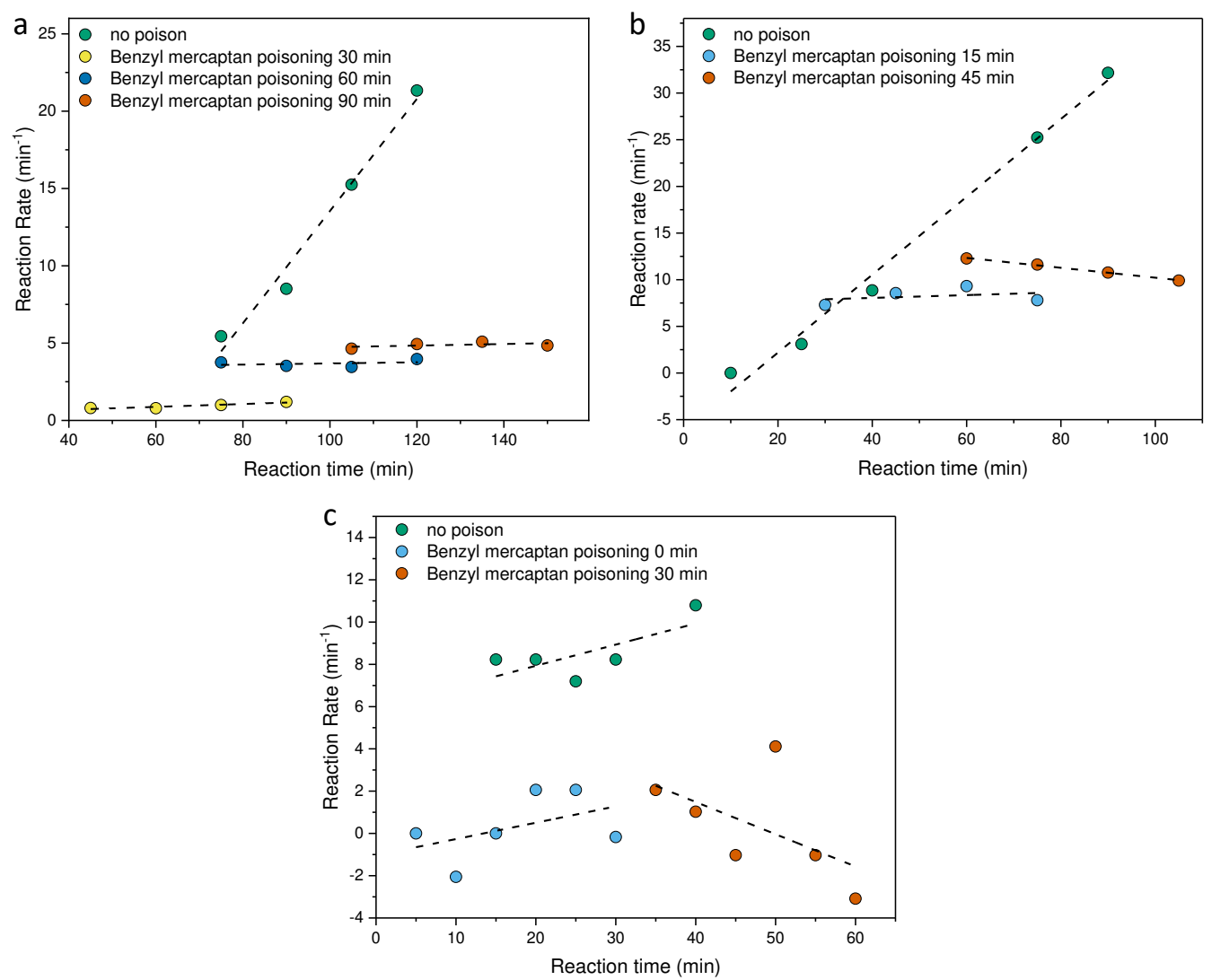

Extended Data Fig. 4 Hydrogenation reaction rates changes after hydrogen spillover. The reaction rates corresponding to Fig. $3 \mathbf{d}-\mathbf{f}$ are plotted here for $\mathbf{a}, \mathrm{NB}, \mathbf{b}, \mathrm{ACP}, \mathbf{c}, \mathrm{VA}$. Reaction conditions: $\mathrm{V}_{\text {total }}=0.02 \mathrm{~L}$ deionised water with $\mathrm{C}_{\mathrm{PMO} 11039}=1 \mathrm{mM}, \mathrm{C}_{\mathrm{Pd}}=0.33 \mathrm{mM}, \mathrm{F}\left(5 \% \mathrm{H}_{2} / \mathrm{N}_{2}\right)=40 \mathrm{~cm}^{3} \mathrm{~min}^{-1}$, $\mathrm{C}_{\text {substrate }}=10 \mathrm{mM}, \mathrm{T}=\mathrm{RT}(\mathbf{a}), 40(\mathbf{b})$, or $0{ }^{\circ} \mathrm{C}(\mathbf{c})$; benzyl mercaptan to a final $\mathrm{C}_{\text {mercaptan }}=0.66 \mathrm{mM}$ was added at different time points. 


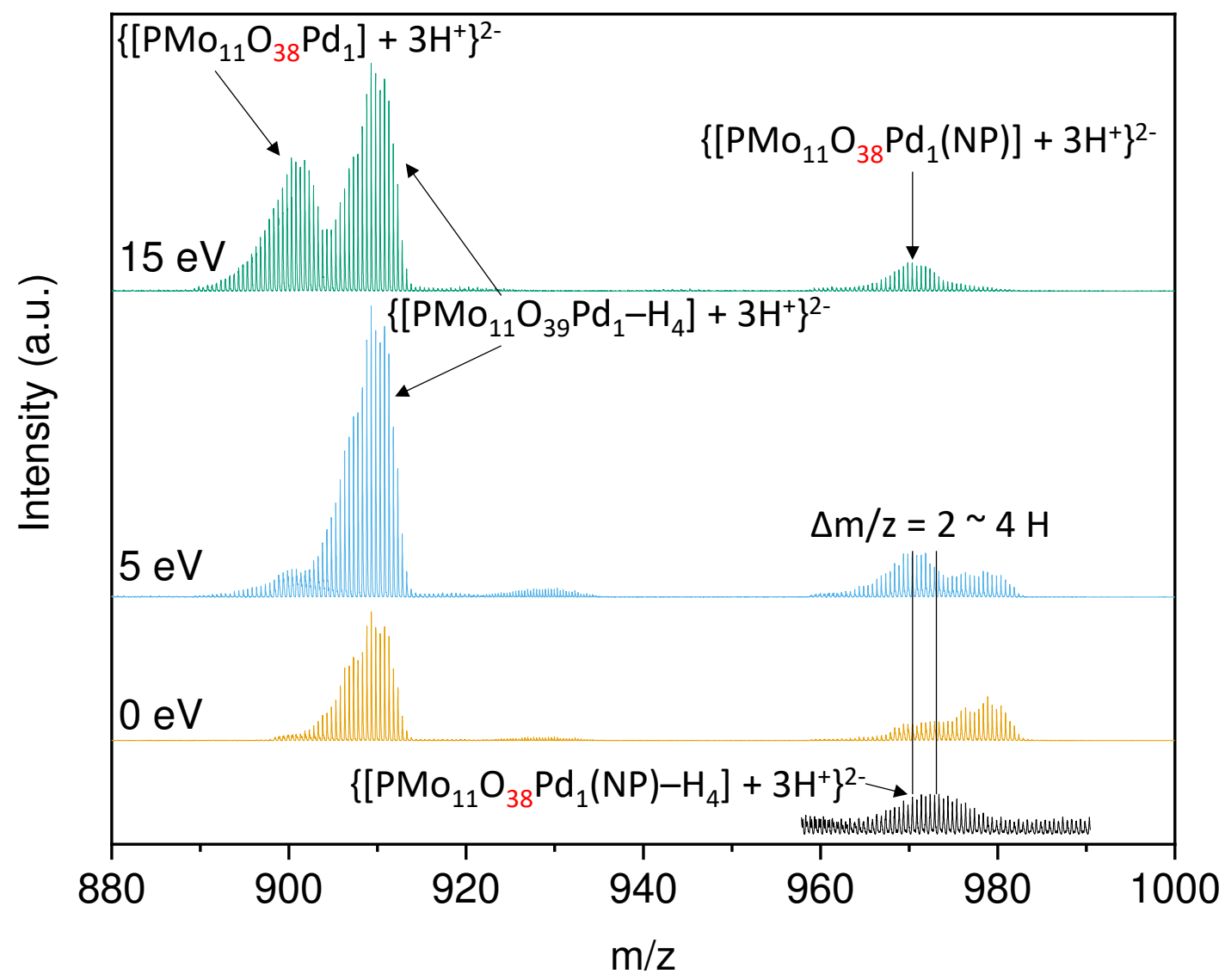

Extended Data Fig. 5 | Gas phase reactivity between the oxygen vacant $\mathrm{PMo}_{11} \mathrm{O}_{38} \mathrm{Pd}_{\mathbf{1}}$ and NP. For the gas phase fragmentation, the molecules species $\left\{\left[\mathrm{PMo}_{11} \mathrm{O}_{38} \mathrm{Pd}_{1}(\mathrm{NP})-\mathrm{H}_{4}\right]+3 \mathrm{H}^{+}\right\}^{2-}$ (calc.: 972.37 , expt.: 972.37) has been mass-selected and subjected to MS/MS analysis at increasing fragmentation energies. Reaction conditions: $\mathrm{V}_{\text {total }}=0.02 \mathrm{~L}$ deionised water with $\mathrm{C}_{\mathrm{PMo11039}}=1 \mathrm{mM}, \mathrm{C}_{\mathrm{Pd}}=0.5 \mathrm{mM}, \mathrm{F}$ $\left(5 \% \mathrm{H}_{2} / \mathrm{N}_{2}\right)=40 \mathrm{~cm}^{3} \mathrm{~min}^{-1}, \mathrm{C}_{\text {substrate }}=25 \mathrm{mM}, \mathrm{t}=30 \mathrm{~min}, \mathrm{~T}=\mathrm{RT}$. 
a

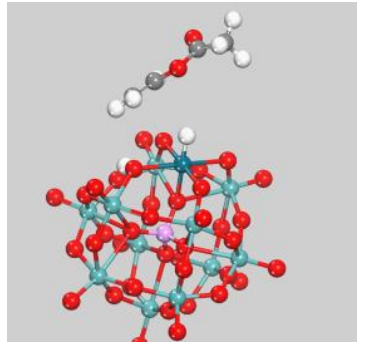

b

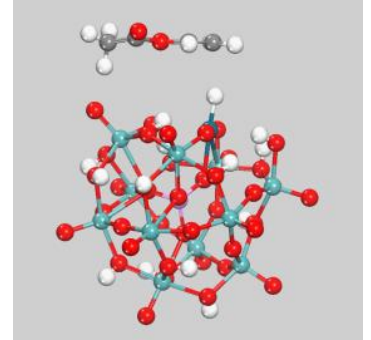

C

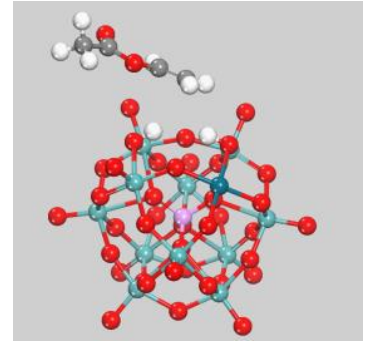

d

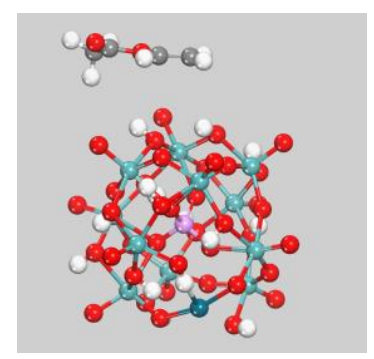

$\rightarrow$

$E_{a}=0.07 e V$

$\mathrm{H}=-0.26 \mathrm{eV}$
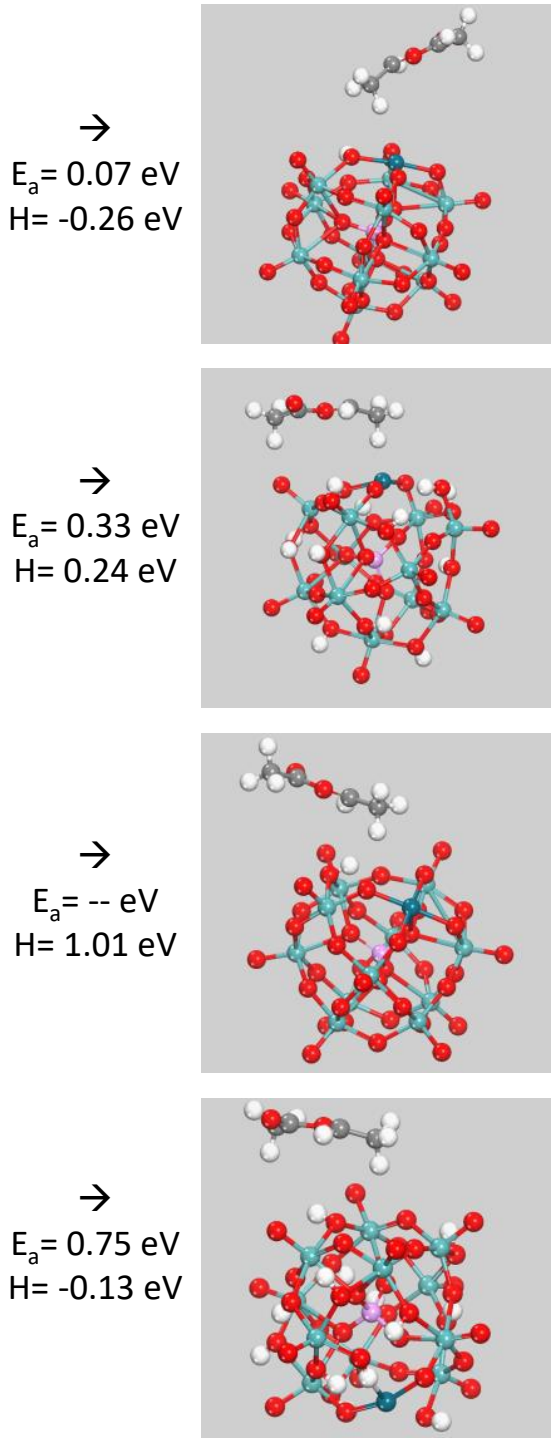

Extended Data Fig. 6 | Structures and reaction energies for the VA hydrogenation over PMo${ }_{11} \mathbf{O}_{39} \mathbf{P d}_{1}$. Two different hydrogenation sites were considered: Either in the proximity of Pd entailing the transfer of one $\mathrm{H}$ atom from $\mathrm{Pd}$ and one from the support $(\mathbf{a}, \mathbf{b})$ or solely with two $\mathrm{H}$ atoms from the support (c, d). Furthermore, two different $\mathrm{H}$ coverages were considered for both types of active sites: $\mathrm{PMo}_{11} \mathrm{O}_{39} \mathrm{Pd}_{1}-\mathrm{H}_{2}(\mathbf{a}, \mathbf{c})$ and $\mathrm{PMo}_{11} \mathrm{O}_{39} \mathrm{Pd}_{1}-\mathrm{H}_{14}(\mathbf{b}, \mathbf{d})$. 
a

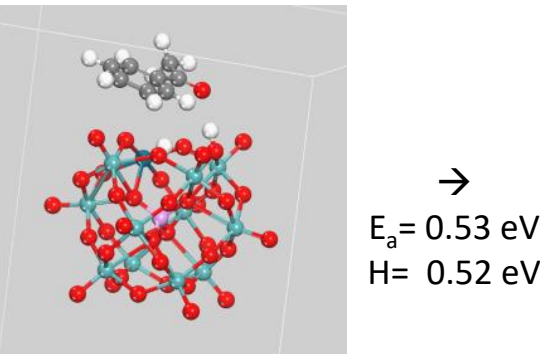

b

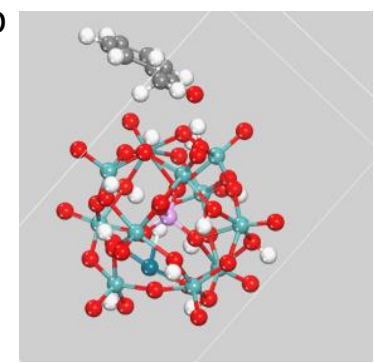

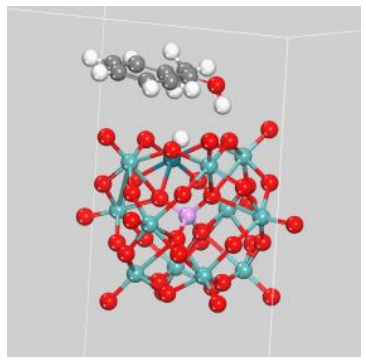
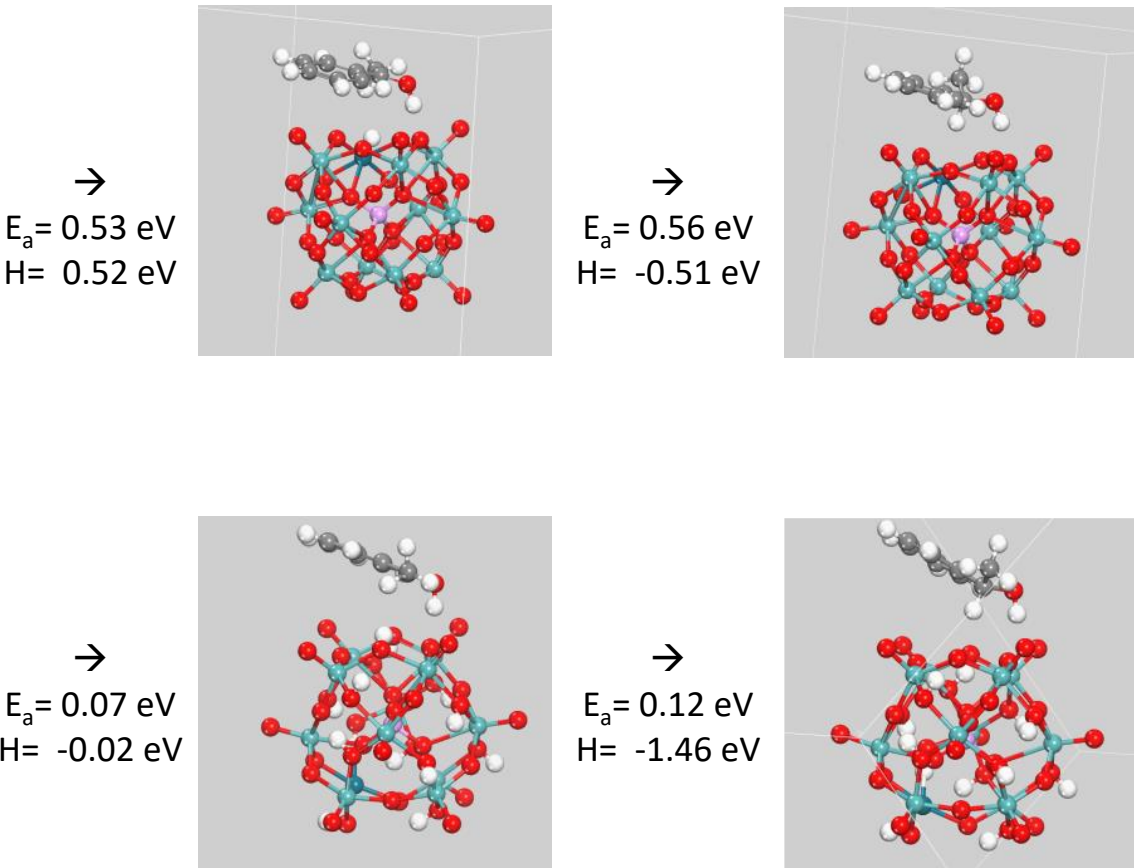
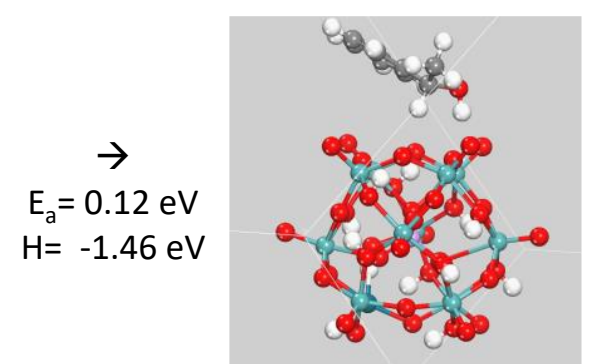

Extended Data Fig. 7 | Structures of $\mathrm{PMo}_{11} \mathrm{O}_{39} \mathrm{Pd}_{1}$ with varying $\mathrm{H}$ coverages during $\mathrm{ACP}$ hydrogenation. Catalyst structures under a, low coverages $\left(\mathrm{PMo}_{11} \mathrm{O}_{39} \mathrm{Pd}_{1}-\mathrm{H}_{2}\right)$ and $\mathbf{b}$, high $\mathrm{H}$ coverages $\left(\mathrm{PMo}_{11} \mathrm{O}_{39} \mathrm{Pd}_{1}-\mathrm{H}_{14}\right)$. 

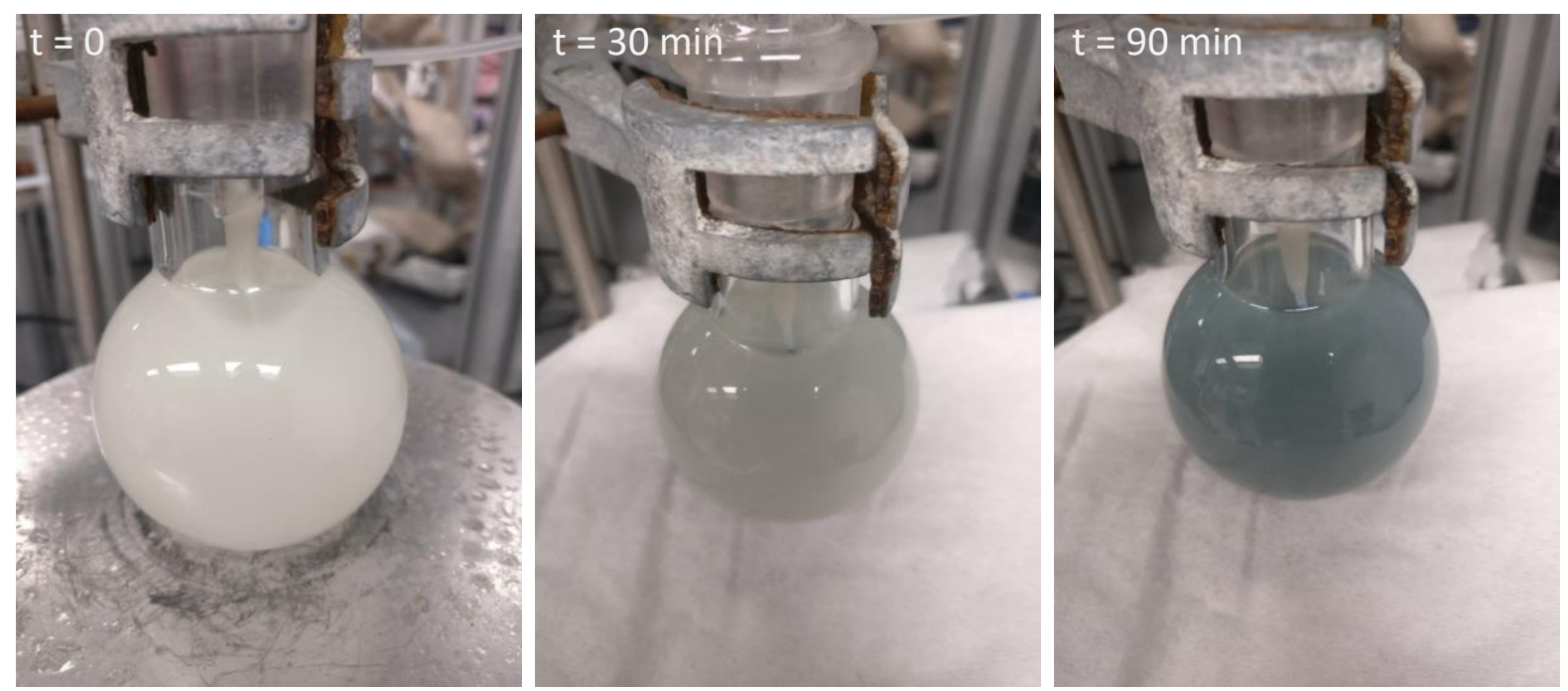

Extended Data Fig. 6 | Hydrogen spillover on 1 wt \% Pt/WO 3 . Photographs of the Pt/WO 3 -containing dispersion after $\mathrm{H}_{2}$ exposure for different durations. Reaction conditions: $\mathrm{V}_{\text {total }}=0.04 \mathrm{~L}$ deionised water with $\mathrm{m}_{\mathrm{P} / \mathrm{WO} 3}=0.05 \mathrm{~g}, \mathrm{~F}\left(5 \% \mathrm{H}_{2} / \mathrm{N}_{2}\right)=40 \mathrm{~cm}^{3} \mathrm{~min}^{-1}, 1500 \mathrm{rpm}, \mathrm{T}=\mathrm{RT}$. 


\section{Supplementary Files}

This is a list of supplementary files associated with this preprint. Click to download.

- Sl.docx 